\title{
Estimation of fire-induced carbon emissions from Equatorial Asia in 2015 using in situ aircraft and ship observations
}

\author{
Yosuke Niwa $^{1,2}$, Yousuke Sawa ${ }^{2, a}$, Hideki Nara ${ }^{1}$, Toshinobu Machida ${ }^{1}$, Hidekazu Matsueda $^{2, b}$, Taku Umezawa ${ }^{1}$, \\ Akihiko Ito $^{1}$, Shin-Ichiro Nakaoka ${ }^{1}$, Hiroshi Tanimoto ${ }^{1}$, and Yasunori Tohjima ${ }^{1}$ \\ ${ }^{1}$ National Institute for Environmental Studies, Tsukuba, Japan \\ ${ }^{2}$ Meteorological Research Institute, Tsukuba, Japan \\ ${ }^{a}$ now at: Japan Meteorological Agency, Tokyo, Japan \\ b now at: Dokkyo University, Soka, Japan
}

Correspondence: Yosuke Niwa (niwa.yosuke@ nies.go.jp)

Received: 4 December 2020 - Discussion started: 23 December 2020

Revised: 5 May 2021 - Accepted: 20 May 2021 - Published: 23 June 2021

\begin{abstract}
Inverse analysis was used to estimate fire carbon emissions in Equatorial Asia induced by the big El Niño event in 2015. This inverse analysis is unique because it extensively used high-precision atmospheric mole fraction data of carbon dioxide $\left(\mathrm{CO}_{2}\right)$ from the commercial aircraft observation project CONTRAIL. Through comparisons with independent shipboard observations, especially carbon monoxide (CO) data, the validity of the estimated fire-induced carbon emissions was demonstrated. The best estimate, which used both aircraft and shipboard $\mathrm{CO}_{2}$ observations, indicated $273 \mathrm{Tg}$ C for fire emissions from September-October 2015. This 2-month period accounts for $75 \%$ of the annual total fire emissions and $45 \%$ of the annual total net carbon flux within the region, indicating that fire emissions are a dominant driving force of interannual variations of carbon fluxes in Equatorial Asia. Several sensitivity experiments demonstrated that aircraft observations could measure fire signals, though they showed a certain degree of sensitivity to prior fire-emission data. The inversions coherently estimated smaller fire emissions than the prior data, partially because of the small contribution of peatland fires indicated by enhancement ratios of $\mathrm{CO}$ and $\mathrm{CO}_{2}$ observed by the ship. In future warmer climate conditions, Equatorial Asia may experience more severe droughts, which risks releasing a large amount of carbon into the atmosphere. Therefore, the continuation of aircraft and shipboard observations is fruitful for reliable monitoring of carbon fluxes in Equatorial Asia.
\end{abstract}

\section{Introduction}

Equatorial Asia, which includes Indonesia, Malaysia, Papua New Guinea and the surrounding areas (Fig. 1) has experienced extensive biomass burning, especially during drought conditions induced by El Niño and the Indian Ocean dipole (Field et al., 2009). This biomass burning has emitted a significant amount of carbon, mainly in the form of carbon dioxide $\left(\mathrm{CO}_{2}\right)$, into the atmosphere (Page et al., 2002; Patra et al., 2005; van der Werf et al., 2008). Much of these fireinduced carbon emissions in Equatorial Asia came from peatland, which has a remarkably high carbon density. Since the peatland in Equatorial Asia accounts for a significant portion of the global peatland (Page et al., 2011), the region has a distinct role in the global carbon cycle despite its small terrestrial coverage.

In 2015 , the extreme El Niño, accompanied by a positive anomaly of the Indian Ocean dipole, induced severe drought and devastating biomass burning in Equatorial Asia. This was one of biggest El Niño events in the last 30 years, rivalling the well-known major El Niño in 1997/1998 (L'Heureux et al., 2017; Santoso et al., 2017). Page et al. (2002) estimated that the biomass burning in 1997 emitted a massive amount of carbon into the atmosphere, ranging between 810 and $2570 \mathrm{TgC}$.

Compared to 1997 , more observations were available in 2015, and several studies used those observations to estimate the fire-induced carbon emissions. Field et al. (2016) reported that the annual total carbon emissions induced by 


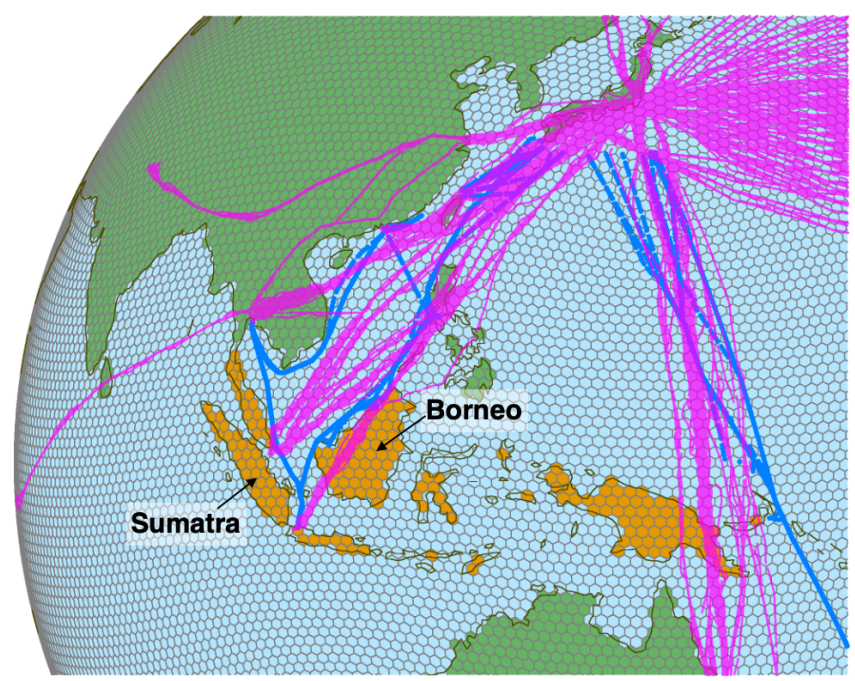

Figure 1. Locations of the observations obtained by CONTRAIL (magenta) and NIES VOS (blue) for November 2014-January 2016. Pentagons and hexagons in grey denote the icosahedral grids of NICAM (the grid interval is $\sim 112 \mathrm{~km}$ ); those filled in orange indicate Equatorial Asia, the target region of this study.

the fires in 2015 was $380 \mathrm{TgC}$, which was based on the Global Fire Emissions Database version 4s (GFED4s; Mu et al., 2011; Randerson et al., 2012; Giglio et al., 2013; van der Werf et al., 2017). The GFED4s data are derived from active fire data from the Moderate Resolution Imaging Spectroradiometers (MODIS) onboard the Terra and Aqua satellites. Huijnen et al. (2016) estimated the emissions to be $289 \mathrm{Tg} \mathrm{C}$ by combining total column carbon monoxide (CO) data from the satellite Measurements of Pollution in the Troposphere (MOPITT) with emission factors estimated from local measurements of smoke. In their estimate, the fireinduced $\mathrm{CO}$ emission data from the Global Fire Assimilation System (GFAS v1.2; Kaiser et al., 2012) were modified to be consistent with the MOPITT CO observations, resulting in a downward shift from the original estimate of GFAS v1.2. Yin et al. (2016) also used the column CO data from MOPITT for estimating the carbon emissions in Equatorial Asia. They used multi-tracer (CO, methane and formaldehyde) inverse analysis data (Yin et al., 2015) and estimated $122 \mathrm{Tg}$ of fire-emitted CO for 2015. With a prescribed ratio of the emission factors between total carbon and $\mathrm{CO}$, this number leads to $510 \mathrm{Tg} \mathrm{C}$ for the total carbon emissions.

The total carbon emission estimates of the above studies were obtained from the fire-related data of MODIS and atmospheric $\mathrm{CO}$ mole fractions of MOPITT and not from observations of atmospheric $\mathrm{CO}_{2}$, which is the major constituent of emitted carbon. Heymann et al. (2017) first used atmospheric $\mathrm{CO}_{2}$ mole fraction data to estimate the fireinduced carbon emissions in Equatorial Asia for 2015. They used the column-averaged dry-air mole fraction of $\mathrm{CO}_{2}$ from the Orbiting Carbon Observatory-2 satellite (Crisp et al.,
2008; Crisp, 2015) and obtained a $\mathrm{CO}_{2}$ emissions estimate of $748 \mathrm{Mt} \mathrm{CO}_{2}$ (equivalent to $204 \mathrm{Tg} \mathrm{C}$ ) from July to November 2015 , which covers the beginning and end of the fire season. Their estimate was $35 \%$ and $30 \%$ smaller than the MODISbased emission estimates of GFED4s and GFAS v1.2, respectively. This lower estimate is more consistent with the estimate of Huijnen et al. (2016) than that of Yin et al. (2015).

Thus, the estimates of the fire-induced carbon emissions in Equatorial Asia for 2015 are still uncertain, though they are consistently much smaller than those of 1997 . As discussed by Field et al. (2009, 2016) and Yin et al. (2016), a nonlinear sensitivity of the fire emissions to the climate conditions contributed to the notable discrepancy of the fireemission amount between 1997 and 2015. However, the underlying mechanisms are unclear, and further investigation and a more accurate emissions estimate are required. Importantly, the previous studies mainly relied on satellite data of atmospheric $\mathrm{CO}_{2}$ or $\mathrm{CO}$. These estimates have possible errors because satellite data are not well retrieved when there are smoke or clouds. Heavy smoke occurred from the fires in 2015 (Field et al., 2016). Furthermore, cumulus clouds are frequent over Equatorial Asia, although convective activity decreases during the dry season.

In this study, we estimated carbon emissions in Equatorial Asia for 2015 using in situ atmospheric observations by aircraft and ship. The observational data were obtained from the commercial aircraft observation project Comprehensive Observation Network for TRace gases by AIrLiner (CONTRAIL; Machida et al., 2008) and the National Institute for Environmental Studies (NIES) Volunteer Observing Ship (VOS) Programme (Tohjima et al., 2005; Terao et al., 2011; Nakaoka et al., 2013; Nara et al., 2011, 2014, 2017). Because of the in situ measurements, the observational data provide much higher accuracy than the satellite observations used in previous studies. The moderate distance of the observational locations from the source areas (i.e. in the free troposphere or offshore) should ensure enough spatial representativeness of the observations in the inverse analysis. Given the sparse ground-based observations in Equatorial Asia, these programmes provide valuable opportunities to investigate the fire-induced emissions in the region. The longterm aircraft observation (the predecessor of CONTRAIL) observed $\mathrm{CO}_{2}$ and $\mathrm{CO}$ mole fraction variations associated with El Niño over the western Pacific since 1993 (Matsueda et al., 2002, 2019). Its occasional flights to Singapore (Matsueda and Inoue, 1999) and a campaign flight over Australia and Indonesia (Sawa et al., 1999) captured pronounced elevations of CO from the Equatorial fires in 1997. Furthermore, Nara et al. (2017) observed prominent $\mathrm{CO}_{2}$ and $\mathrm{CO}$ enhancements from the peatland fires in Equatorial Asia in 2013 by NIES VOS.

To link the atmospheric observations to surface carbon fluxes, we performed an inverse analysis of atmospheric $\mathrm{CO}_{2}$ using the Nonhydrostatic Icosahedral Atmospheric Model (NICAM; Tomita and Satoh, 2004; Satoh et al., 2008, 2014)- 
based Inverse Simulation for Monitoring $\mathrm{CO}_{2}$ (NISMON$\mathrm{CO}_{2}$ ) (formerly NICAM-TM 4D-Var; Niwa et al., 2017a, b). The inversion system uses the NICAM-based transport model (NICAM-TM; Niwa et al., 2011). Using the same atmospheric transport model, Niwa et al. (2012) performed a $\mathrm{CO}_{2}$ inverse analysis and demonstrated a strong constraint of the CONTRAIL data for Equatorial Asia. In this study, we estimated surface fluxes at a higher resolution using a more sophisticated inversion method than that of Niwa et al. (2012), namely the four-dimensional variational (4D-Var) method (Niwa et al., 2017a). The 4D-Var estimates fluxes at a model grid resolution to address flux signals from spatially limited phenomena such as biomass burning. We newly implemented CO into the inverse system to evaluate combustion sources. In our inverse analysis, we predominantly used atmospheric $\mathrm{CO}_{2}$ observations from CONTRAIL and evaluated the inversion results using independent $\mathrm{CO}_{2}$ and $\mathrm{CO}$ observations from NIES VOS. Finally, we performed an inverse analysis using both the CONTRAIL and NIES VOS $\mathrm{CO}_{2}$ observations to enhance the reliability of the inverse analysis.

\section{Methods}

\subsection{Observations}

In this inverse analysis, we only used the CONTRAIL and NIES VOS data, because they are predominant in the area we focused on. Here, we briefly describe those observations and further information can be found in the literatures cited therein

\subsubsection{CONTRAIL}

The CONTRAIL data were obtained from in situ $\mathrm{CO}_{2}$ measurements by continuous $\mathrm{CO}_{2}$ measurement equipment (CME), which is installed onboard the Boeing 777-200ER and -300ER of Japan Airlines (Machida et al., 2008; Sawa et al., 2012; Umezawa et al., 2018). For the analysis period from November 2014 to January 2016, the total number of CONTRAIL-CME data exceeds 1.3 million, comprising $10 \mathrm{~s}$ interval data from ascending or descending sections and 1 min interval data from cruising sections. In the analysis, we only used data in the free troposphere, derived by excluding data in the stratosphere and the planetary boundary layer identified by thresholds of two potential vorticity units (PVUs; $1 \mathrm{PVU}=10^{-6} \mathrm{~m}^{2} \mathrm{~s}^{-1} \mathrm{~K} \mathrm{~kg}^{-1}$ ) and $R i=0.25(R i$ is the bulk Richardson number), respectively (Sawa et al., 2008, 2012). This data filtering is needed because the signals of surface fluxes are efficiently attenuated in the stratosphere, and lower altitude data could be affected by local emissions from a neighbouring city or an airport (Umezawa et al., 2020). After filtering, the number of observations is still as large as 1.1 million. In particular, the observational coverage for Equatorial Asia is noteworthy, which is predominantly the result of high-frequency flights between Japan and Singapore.

\subsubsection{NIES VOS programme}

The NIES VOS programme has been conducting atmospheric and surface ocean observations in the Pacific Ocean using commercial cargo vessels (Tohjima et al., 2005; Terao et al., 2011; Nakaoka et al., 2013; Nara et al., 2011, 2014, 2017). The observation network ranges from Japan to North America, Oceania (Australia and New Zealand), and Southeast and Equatorial Asia. In 2015, the vessel Fujitrans World (owned by the Kagoshima Senpaku Co., Ltd., Kagoshima, Japan) was used for observations in Southeast and Equatorial Asia. Onboard the ship, an in situ measurement system continuously observed atmospheric mole fractions of greenhouse gases and other related atmospheric species (Nara et al., 2017). In this study, in addition to $\mathrm{CO}_{2}$, atmospheric $\mathrm{CO}$ data were used for the proxy of fire-induced emissions. The ship normally travels once a month, but for $2015 \mathrm{ob}$ servational data were obtained in January and from May to November. It takes approximately two weeks to travel around Southeast and Equatorial Asia. In this study, we used $1 \mathrm{~h}$ interval data that passed careful quality control. Using ancillary data of the cruising speed and mole fractions of related species (e.g. ozone), the quality control excluded mole fraction data of $\mathrm{CO}_{2}$ and $\mathrm{CO}$ that were judged as the ship's exhaust and contaminated by local ports.

\subsection{Inverse analysis}

\subsubsection{Inversion system and transport model}

Similar to previous inversions (e.g. Baker et al., 2006; Chevallier et al., 2010; Rödenbeck, 2005), the inverse analysis of this study is based on Bayesian estimation (e.g. Rayner et al., 1996; Enting, 2002). The cost function is defined as

$$
\begin{aligned}
J(\delta \boldsymbol{x}) & =\frac{1}{2} \delta \boldsymbol{x}^{\mathrm{T}} \mathbf{B}^{-1} \delta \boldsymbol{x}+\frac{1}{2}\left(M\left(\boldsymbol{x}_{0}+\delta \boldsymbol{x}\right)-\boldsymbol{y}\right)^{\mathrm{T}} \\
& \times \mathbf{R}^{-1}\left(M\left(\boldsymbol{x}_{0}+\delta \boldsymbol{x}\right)-\boldsymbol{y}\right),
\end{aligned}
$$

where $\delta \boldsymbol{x}$ is the control vector, including parameters to be optimised, $\boldsymbol{y}$ represents the vector of observations and $\boldsymbol{x}_{0}$ denotes the basic model state of the parameters. The matrices $\mathbf{B}$ and $\mathbf{R}$ are the prescribed error covariance for $\delta \boldsymbol{x}$ and the model-observation mismatch, respectively. The operator $M($.$) describes the forward simulation, including linear$ spatio-temporal interpolation to each observational location and time. In this inverse analysis, $\boldsymbol{x}_{0}$ and $\delta \boldsymbol{x}$ comprise prescribed surface $\mathrm{CO}_{2}$ flux data and deviations from them, respectively, and the operator $M($.) represents the atmospheric transport. Atmospheric mole fraction observations of $\mathrm{CO}_{2}$ are inputs to the vector $\boldsymbol{y}$.

In this study, we used the 4D-Var method to obtain an optimal vector $\delta \boldsymbol{x}$ that minimises the cost function. In this method, an optimal parameter vector is sought by iterative calculations using the gradient of the cost function,

$\nabla J_{\delta \boldsymbol{x}}=\mathbf{B}^{-1} \delta \boldsymbol{x}+\mathbf{M}^{\mathrm{T}} \mathbf{R}^{-1}\left(M\left(\boldsymbol{x}_{0}+\delta \boldsymbol{x}\right)-\boldsymbol{y}\right)$, 
where $\mathbf{M}^{\mathrm{T}}$ is the transpose of the tangent linear operator $\mathbf{M}$ (in this study, $\mathbf{M} \delta \boldsymbol{x} \approx M(\delta \boldsymbol{x})$ because of the linearity of the problem). The $\mathbf{M}^{\mathrm{T}}$ calculation requires an adjoint model.

The inversion system NISMON is specifically designed for the inverse analysis of an atmospheric constituent (Niwa et al., 2017a, b). In the system, the forward model of NICAM-TM simulates atmospheric mole fractions from given surface fluxes, and its adjoint model calculates the sensitivities of fluxes against atmospheric mole fractions (Niwa et al., 2017b). Specifically, the continuous adjoint model was chosen for the adjoint calculation, assuring monotonicity of tracer concentrations and sensitivities at the expense of minor nonlinearity (Niwa et al., 2017b). The optimisation calculation uses the quasi-Newtonian algorithm of the Preconditioned Optimizing Utility for Large-dimensional analyses (POpULar; Fujii and Kamachi, 2003; Fujii, 2005; Niwa et al., 2017a).

The atmospheric transport model NICAM-TM adopts an icosahedral grid system with hexagon- or pentagon-shaped grids (Fig. 1) that are produced by the recursive division of an icosahedron. All the model simulations were performed at a horizontal resolution of glevel- 6 ( $n$ of glevel- $n$ denotes the number of divisions of an icosahedron, representing the level of the model horizontal resolution). The averaged grid interval of glevel- 6 is $112 \mathrm{~km}$, sufficiently resolving the major archipelagos in Equatorial Asia (Fig. 1). For forward and adjoint simulations of atmospheric transport, archived meteorological data drive NICAM-TM, which is an offline calculation. The meteorological data were prepared in advance from the simulation of the parent model NICAM, whose wind fields are nudged towards Japanese 55-year reanalysis data (JRA-55; Kobayashi et al., 2015; Harada et al., 2016) (see Niwa et al., 2017b for a detailed description of the archived meteorological data). Other model settings can be found in Niwa et al. (2017b).

\subsubsection{Implementation of $\mathrm{CO}$}

In this study, we newly implemented a $\mathrm{CO}$ function in the above inversion system to use $\mathrm{CO}$ as a proxy for fireinduced emissions. It also considers oxidation from $\mathrm{CO}$ to $\mathrm{CO}_{2}$, which could have measurable effects on $\mathrm{CO}_{2}$ observations near fires. Figure 2 shows a schematic diagram for the forward and adjoint simulations of NICAM-TM, including $\mathrm{CO}$. This $\mathrm{CO}$ function considers only the chemical reaction with hydroxyl radicals $(\mathrm{OH})$. The $\mathrm{OH}$ fields are given as input data; hence, the model does not have nonlinear chemical reactions and thus retains its linearity, which is assumed in the inverse analysis theory. Furthermore, the oxidation from methane $\left(\mathrm{CH}_{4}\right)$ to $\mathrm{CO}$ with $\mathrm{OH}$ is also considered. For simplicity, however, the atmospheric mole fraction of $\mathrm{CH}_{4}$ was set at a globally constant value of $1844 \mathrm{ppb}$ $\left(=10^{-9} \mathrm{~mol}^{-1}\right)$, which was derived from the global annual mean mole fraction for 2015, reported by the World Data Center for Greenhouse Gases (WDCGG; WMO, 2018).

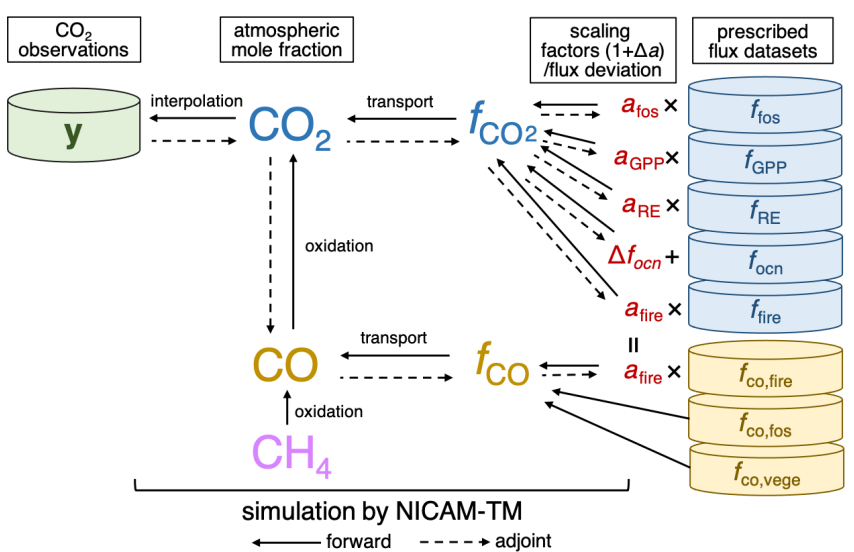

Figure 2. Schematic diagram of the $\mathrm{CO}_{2}-\mathrm{CO}$ forward/adjoint calculations in NICAM-TM.

The atmospheric three-dimensional data of $\mathrm{OH}$ were derived from the TransCom- $\mathrm{CH}_{4}$ project (Spivakovsky et al., 2000; Patra et al., 2011). In the model, the contribution of oxidation from biogenic volatile organic compounds (BVOCs) to $\mathrm{CO}$ is not considered yet, but direct $\mathrm{CO}$ emissions from vegetation are given at the Earth's surface. Although the oxidations of $\mathrm{CH}_{4}$ and BVOCs are significant sources of atmospheric $\mathrm{CO}$, we treated the former very simply and did not consider the latter. Therefore, we did not input $\mathrm{CO}$ observations to the inverse analysis. In the inversion, the biomass burning emissions of $\mathrm{CO}$, which were predominant in Equatorial Asia, were modified along with those of $\mathrm{CO}_{2}$, as described in the next section.

\subsubsection{Flux model}

As described in Fig. 2, we introduced scaling factors to surface fluxes, which is another updated feature of the inversion system from Niwa et al. (2017a). The surface $\mathrm{CO}_{2}$ flux input to the model, $f_{\mathrm{CO}_{2}}$, is described as

$$
\begin{aligned}
f_{\mathrm{CO}_{2}}(x, t) & =\left(1+\Delta a_{\mathrm{fos}}(x, t)\right) f_{\text {fos }}(x, t) \\
& -\left(1+\Delta a_{\mathrm{GPP}}(x, t)\right) f_{\mathrm{GPP}}(x, t) \\
& +\left(1+\Delta a_{\mathrm{RE}}(x, t)\right) f_{\mathrm{RE}}(x, t) \\
& +\left(1+\Delta a_{\text {fire }}(x, t)\right) f_{\text {fire }}(x, t) \\
& +f_{\text {ocn }}(x, t)+\Delta f_{\mathrm{ocn}}(x, t),
\end{aligned}
$$

where $x$ and $t$ indicate flux location and time, and $f$ represents prescribed flux data, whose subscripts of fos, GPP, RE, fire and ocn denote flux components of fossil fuel combustion and cement production, gross primary production (GPP) and respiration (RE) of the terrestrial biosphere, biomass burning and ocean, respectively. Note that a positive value indicates a flux towards the atmosphere. Each flux component could have different temporal resolutions (e.g. monthly, daily), and flux values are linearly interpolated in time to each model time step. Datasets used for each flux component 
are described in the following section. Their coefficients of $\Delta a_{\mathrm{fos}}, \Delta a_{\mathrm{GPP}}, \Delta a_{\mathrm{RE}}$ and $\Delta a_{\text {fire }}$ are scaling factors for corresponding flux components, of which the values could be varied at each model grid. We did not apply the scaling factor to the ocean flux but introduced the deviation of the prescribed flux $\Delta f_{\text {ocn }}$ because the ocean flux has both negative and positive values and its spatio-temporal flux phase could not be modified when introducing a scaling factor. Note that the other flux components should have all positive values. The phases of spatio-temporal variations of terrestrial biosphere flux (e.g. seasonal cycle) could be modified because GPP and RE are separately optimised. The above scaling factors and $\Delta f_{\text {ocn }}$ were the parameters to be optimised in the inverse analysis.

For the surface $\mathrm{CO}$ flux, we considered fossil fuel, vegetation and biomass burning emissions. For the biomass burning emissions, we imposed a common scaling factor with that of $\mathrm{CO}_{2}$. Therefore, in the inversion, the biomass burning emissions of $\mathrm{CO}$ was modified along with that of $\mathrm{CO}_{2}$. The modification of the biomass burning emissions could also be made by signals transported via atmospheric $\mathrm{CO}$ that should have oxidised to $\mathrm{CO}_{2}$ (Fig. 2).

In Eq. (3), the temporal resolution of a flux-scaling factor could be different from that of its corresponding flux and be different by region (Table 1). In this study, we set a daily temporal resolution for the scaling factors of GPP, RE and biomass burning emissions in Equatorial Asia so that the inversion could exploit the full information of those surface fluxes from the observations. For the rest of the region, we set monthly temporal resolutions. For the scaling factor of fossil fuel emissions, we set an annual temporal resolution for Equatorial Asia, and we did not optimise the flux for the rest of the region, i.e. the modification factor was set to 0 . We set a monthly temporal resolution for the deviation of the ocean flux.

\subsubsection{Error covariance matrices}

As in the case for the different flux temporal resolutions, we constructed the flux error covariance matrix $\mathbf{B}$ for Equatorial Asia and the rest of the world separately. Table 1 summarises the standard errors and error correlations that were introduced into the diagonal and off-diagonal elements of B, respectively. For GPP and RE, we assume $40 \%$ error for daily fluxes in Equatorial Asia and $10 \%$ for monthly fluxes in the rest of the world, which means 0.16 and 0.01 for the diagonal elements of $\mathbf{B}$. The higher standard error for Equatorial Asia allows observations to modify surface fluxes sufficiently. Nevertheless, a $3 \mathrm{~d}$ temporal error correlation was introduced to stabilise flux estimates. The smaller standard error for the rest of the world had to constrain the surface flux to the prior because we did not use enough observations to cover the globe. Furthermore, for stabilisation, a spatial error correlation length scale of $1000 \mathrm{~km}$ was introduced. The above error correlations were defined by the Gaussian func- tion (Niwa et al., 2017a). Similarly, $80 \%$ and $100 \%$ errors for fire emissions were introduced for Equatorial Asia and the rest of the world, respectively, but without spatial error correlations. Note that the fire errors for Equatorial Asia are practically larger than $80 \%$, because the $3 \mathrm{~d}$ temporal correlation inflates the errors. We put a $10 \%$ error on the fossil fuel emissions in Equatorial Asia. For the monthly ocean flux errors, we used the standard deviation of the long-term data (1990-2016) and introduced a spatial error correlation of $3000 \mathrm{~km}$. Table 1 shows each parameter.

\subsubsection{Prescribed flux dataset}

For $f_{\text {fos }}$ and $f_{\text {ocn }}$ in Eq. (3), we used monthly mean data of fossil fuel and cement production emissions from the Carbon Dioxide Information Analysis Center (CDIAC) (Andres et al., 2016) and of air-sea $\mathrm{CO}_{2}$ flux from the Japan Meteorological Agency (Takatani et al., 2014; Iida et al., 2015), respectively. Here, the fossil fuel emissions data for 2015 were produced from the latest gridded CDIAC data for 2013 by scaling with the global total value for 2015 that is preliminarily reported by Le Quéré et al. (2015). For $f_{\mathrm{GPP}}$ and $f_{\mathrm{RE}}$, we used 3-hourly data to resolve the distinct diurnal cycles of terrestrial biosphere flux. These $f_{\mathrm{GPP}}$ and $f_{\mathrm{RE}}$ were originally based on monthly mean data from the CarnegieAmes-Stanford Approach (CASA) model (Randerson et al., 1997) but were modified according to the inversion of Niwa et al. (2012). They were further downscaled in time to 3hourly with $2 \mathrm{~m}$ temperature and downward shortwave radiation data from JRA-55 using the method of Olsen and Randerson (2004).

In the inversion of Niwa et al. (2012), the classical lowresolution inversion method (e.g. Enting, 2002) was used, in which the global terrestrial area was divided into 31 regions, and the scaling factors for those regions were optimised. Furthermore, the inversion used both surface and CONTRAIL data for 2006-2008, and the mean flux data of those three years were used in this study. Therefore, such an integrated flux could produce consistent atmospheric mole factions with the observations from the surface to the upper troposphere, although some discrepancies could arise because of the different analysis period. In this study, these fluxes were optimised based on the CONTRAIL data from the study year and further flux information was exploited using the 4D-Var high-resolution (model grid level) inversion with a specific focus on Equatorial Asia.

For the biomass burning flux of $f_{\text {fire }}$, we used four datasets and performed independent inversions to evaluate sensitivities to the biomass burning data (Table 2). The first is the mean of the GFED4s and GFAS v1.2 (noted as GG). The second and third are from GFED4s (GD) and GFAS v1.2 (GS), respectively. The fourth is made by excluding emissions in Equatorial Asia from GG (NO). For NO, we replaced the biomass burning term of Eq. (3) by $\left(0+\Delta a_{\text {fire }}(x, t)\right) f_{\text {fire }}(x, t)$ in Equatorial Asia, where $f_{\text {fire }}$ is the same as GG. 
Table 1. Temporal resolution, standard error and error correlation of each flux component, which were separately configured for Equatorial Asia and the rest of the world. Note that the ocean flux was optimised by its absolute value and the others by their scaling factors; therefore, the monthly standard deviation (SD) of the long-term data was used for the ocean flux error and ratios were used for the other flux errors. n/a means not applicable.

\begin{tabular}{lll|ll|ll}
\hline \multirow{2}{*}{ Flux } & \multicolumn{2}{l}{ Temporal resolution } & \multicolumn{2}{|c|}{ Standard error } & Error correlation (space/time) \\
\cline { 2 - 7 } component & Eq. Asia & Rest & Eq. Asia & Rest & Eq. Asia & Rest \\
\hline fos & Annual & n/a & $10 \%$ & n/a & None $/$ None & n/a \\
GPP, RE & Daily & Monthly & $40 \%$ & $10 \%$ & None $/ 3 \mathrm{~d}$ & $1000 \mathrm{~km} /$ None \\
fire & Daily & Monthly & $80 \%$ & $100 \%$ & None $/ 3 \mathrm{~d}$ & None/None \\
ocn & n/a & Monthly & n/a & SD & n/a & $3000 \mathrm{~km}$ \\
\hline
\end{tabular}

Table 2. Observation and prior fire-emission data for each inverse analysis experiment.

\begin{tabular}{lll}
\hline $\begin{array}{l}\text { Experiment } \\
\text { name }\end{array}$ & Observation & Fire prior \\
\hline C_GG & CONTRAIL & (GFAS + GFED) / 2 \\
C_GD & CONTRAIL & GFED \\
C_GS & CONTRAIL & GFAS \\
C_NO & CONTRAIL & No fire in Equatorial Asia \\
CV_GG & CONTRAIL, VOS & $($ GFAS + GFED) $/ 2$ \\
\hline
\end{tabular}

For CO, the same biomass burning datasets from GFED4s and GFAS v1.2 were used. Note that both the datasets use similar emission factors of $\mathrm{CO}_{2}$ and $\mathrm{CO}$ based on Akagi et al. (2011); in particular, the same emission factor from Christian et al. (2003) was applied to peatland, from which a large part of the fires arise in Equatorial Asia (van der Werf et al., 2017). The rest of the CO fluxes from fossil fuel use and vegetation were derived from the Emission Database for Global Atmospheric Research (EDGAR) version 4.3.2 (JanssensMaenhout et al., 2019) and the process-based model of terrestrial ecosystems, the Vegetation Integrative SImulator for Trace gases (VISIT; Ito and Inatomi, 2012; Ito, 2019), respectively. In the VISIT simulation, $\mathrm{CO}$ emissions are estimated with the scheme of Guenther (1997) but using an emission factor by Tao and Jain (2005). The emission rates are estimated by light, temperature, vegetation leaf amount and seasonality, and the scheme has been calibrated with observational data. For EDGAR v4.3.2, we used emission data from 2012 (the latest data available) for the simulation of 2015.

\subsubsection{Initial mole fraction field and analysis period}

In addition to the flux-scaling factors, the model parameter vector includes the global offset of atmospheric mole fractions. Therefore, $\delta \boldsymbol{x}$ of Eqs. (1) and (2) is constructed as

$\delta \boldsymbol{x}=\left(\Delta \boldsymbol{a}, \Delta \boldsymbol{f}_{\mathrm{ocn}}, \Delta c\right)^{\mathrm{T}}$, where $\Delta \boldsymbol{a}$ and $\Delta \boldsymbol{f}_{\mathrm{ocn}}$ represent all the modification scaling factors and ocean flux deviations of Eq. (3), respectively, and $\Delta c$ denotes the modification to the global offset. Thus, its corresponding basic state vector $\boldsymbol{x}_{0}$ is described as $\boldsymbol{x}_{0}=\left(1, \ldots, 1, \boldsymbol{f}_{\text {ocn }}, 0\right)^{\mathrm{T}}$. Note that the forward model calculation started from a reasonable spatial gradient, which was prepared in advance by a spin-up calculation. At the beginning of the 4D-Var iterative calculation, all the elements of $\delta \boldsymbol{x}$ were set to zero as the initial estimates.

The target period for this study is the whole year of 2015 . However, in the inverse calculation, two extra months were added before the target period to attenuate the errors in the initial mole fraction fields before the beginning of 2015 , which was inevitable because of the global unique parameter described above $(\Delta c)$. Nevertheless, the initial mole fraction fields are consistent with observations to some extent, as they were prepared by the inversion flux of Niwa et al. (2012). This makes the two-month inversion spin-up reasonable. Furthermore, one more month was also added after the target period to well constrain the fluxes at the end of 2015. Therefore, the inverse calculation period consists of 15 months from November 2014 to January 2016.

\subsection{Notation of sensitivity tests}

As described in Sect. 2.2.5, we performed inversion analyses with four biomass burning datasets (GG, GD, GS and NO). We only used the CONTRAIL data, but with GG, we additionally performed an inversion using the NIES VOS data and CONTRAIL to leverage all available observations, denoting $\mathrm{C}_{-}$and $\mathrm{CV}_{-}$as prefixes, respectively. Thus, we have five inversion results (C_GG, C_GD, C_GS, C_NO and CV_GG) (Table 2). Note that although they used different biomass burning data, prior flux errors for biomass burning (Table 1) were commonly used. It is true even for C_NO whose practical prior uncertainty in Equatorial Asia is $80 \%$ of GG. 


\section{Results}

In this section, we first describe spatio-temporal features of the CONTRAIL and NIES VOS observational data with supplemental model analyses. Then, we show the inversion results and demonstrate their validity by comparing posterior mole fractions of $\mathrm{CO}$ and $\mathrm{CO}_{2}$ with the NIES VOS data.

\subsection{Observational features}

As shown in Fig. 3, the CONTRAIL aircraft flew to Singapore 209 times during 2015. These high-frequency observations show a small but distinct seasonal cycle of $\mathrm{CO}_{2}$ mole fractions around Equatorial Asia, with double peaks in April-May and December, and a minimum in June-October, depending on altitudes and latitudes. Furthermore, the CONTRAIL aircraft frequently observed additional highly elevated mole fractions below $3 \mathrm{~km}$ altitude over Singapore (Fig. 3a, lower panel), which could be attributable to local or regional emissions in Equatorial Asia. The model with the prior flux data produced similar mole fraction elevations; however, their timing and magnitudes were sometimes different from the observations (Fig. 3b). A further model analysis with prior biomass burning data suggested that fire contributions to the observed mole fraction elevations were limited mostly to the latter period of the dry season from mid-August to the beginning of November (Fig. 4b). Nevertheless, a model simulation that separately calculated $\mathrm{CO}_{2}$ mole fractions from other different sources (fossil fuel emissions, terrestrial biosphere and ocean fluxes, and oxidation of $\mathrm{CO}$ ) indicated that these fire contributions are dominant in the $\mathrm{CO}_{2}$ mole fraction variations over Singapore for this period. In the other seasons, the model showed almost no contributions from fire emissions (not shown). In particular, the model showed a distinct fire contribution at the end of September, which elevated mole fractions up to the upper troposphere by $\sim 4 \mathrm{ppm}$. In the observations, although similar mole fraction elevations are found in the upper troposphere, its magnitude is smaller $(\sim 2 \mathrm{ppm})$. Furthermore, the observation shows a slightly later peak that lasted until the beginning of October (Fig. 4a). After that, the observations also captured elevated mole fraction events from mid-October onward. However, the prior model estimate showed smaller fire contributions in October than in September (Fig. 4b), although the simulated total $\mathrm{CO}_{2}$ mole fractions were comparable to the observations (Fig. 3b), indicating that non-fire emissions (e.g. from terrestrial biosphere respiration and fossil fuel emissions) had a certain level of contribution during this period.

Figure 5 shows $\mathrm{CO}_{2}$ and $\mathrm{CO}$ mole fractions observed along the track of the NIES VOS around Equatorial Asia. The NIES VOS observations in both September and October 2015 captured coincident elevations of $\mathrm{CO}_{2}$ and $\mathrm{CO}$ mole fractions in the east of the Malay Peninsula and west of Borneo. By performing a transport simulation of tagged fire-induced $\mathrm{CO}$ tracers (the fire emissions of GG were used here), we found that the fires in Borneo and Sumatra contributed almost every notable mole fraction elevation except for 17 September and 15-16 October, both of which might be contributed by the fossil fuel emissions in Jakarta (Fig. 6). As highlighted by the grey shades in Fig. 6, seven of those events contributed by the fires are designated by $\mathrm{P} 1, \mathrm{P} 2, \ldots$, P7 in this study. These events will be used for evaluating the inverse analysis, especially for fire-emission features, as described in Sect. 3.2.2. Note that mole fraction data from 13-15 September and 11-14 October were excluded before the analysis. During these periods, some data were not correctly obtained because the signals were too large and out of the measurable range. Furthermore, the NIES VOS ship travelled slowly or stayed around the Malacca Straits, resulting in contamination by the ship's own exhaust.

Figure 7 shows sensitivities of the CONTRAIL and NIES VOS observations against surface $\mathrm{CO}_{2}$ fluxes, i.e. footprints, for September and October 2015, calculated by the adjoint model of NICAM-TM (Niwa et al., 2017b). The CONTRAIL footprints represent sensitivities of observations obtained during ascending or descending flights over Singapore (i.e. the data shown in the lower panel of Fig. 4a). For both September and October, the calculated footprints indicate that the CONTRAIL observations could provide significant constraints on flux estimates for Equatorial Asia, especially Borneo (Fig. 7a and b). These widespread footprint features are because the data were obtained in the free troposphere, which is an advantage of aircraft observations in terms of representativeness. Figure 7 also suggests that the constraint is stronger during October than September because the number of data is larger in October (Figs. 3 or 4). Compared to CONTRAIL, the NIES VOS footprints are restricted to the ocean (Fig. 7c and d) because the observations were made within the marine boundary layer. Another contributing factor is the weak wind fields, which are typical in the tropics. Nevertheless, there are some sensitivities of the NIES VOS observations on the coasts of the islands, with which the significantly large fire emissions elevated the mole fractions of atmospheric $\mathrm{CO}_{2}$ and $\mathrm{CO}$ (Figs. 5 and 6).

\subsection{Inversion results}

\subsubsection{Posterior fluxes}

In this study, we investigate surface fluxes by the sum of $\mathrm{CO}_{2}$ and $\mathrm{CO}$ fluxes, defined as a carbon flux. Furthermore, we evaluate the carbon flux separately for the total net flux and biomass burning emissions. Note that the total net flux includes terrestrial biosphere fluxes, biomass burnings emissions and fossil fuel emissions.

Table 3 summarises the total net and fire carbon fluxes of Equatorial Asia estimated by the five sets of inversions. The prior biomass burning emissions of GG, GD and GS are consistently $300 \mathrm{Tg} C$ for September-October, which consti- 
(a) Observation
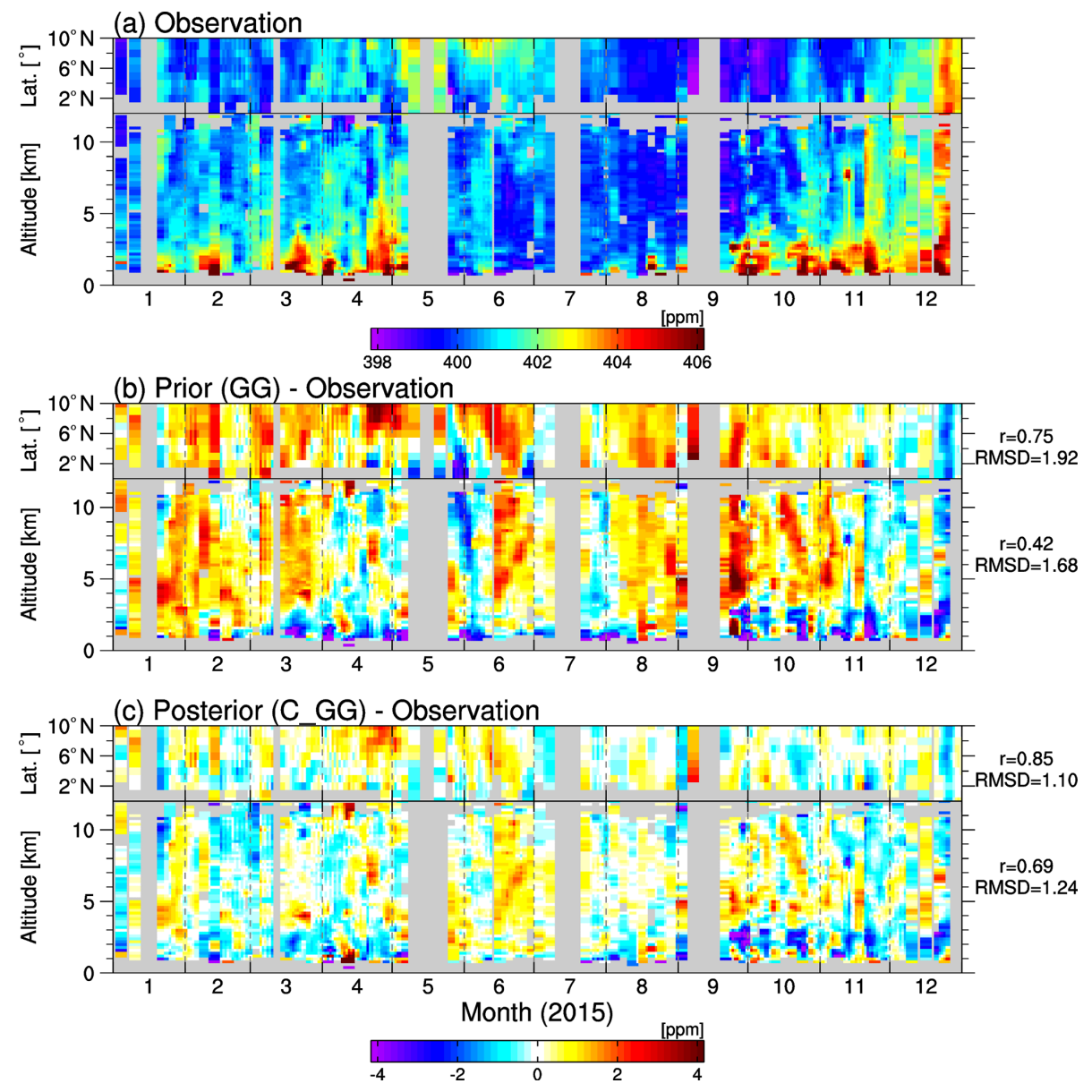

Figure 3. $\mathrm{CO}_{2}$ mole fractions in the free troposphere around Equatorial Asia (note that data in the boundary layer and stratosphere are excluded; see the main text) observed by CONTRAIL (a) and their corresponding prior (GG) (b) and posterior (C_GG) (c) model values deviated from the observations. Each upper panel presents a time-latitude cross section from cruising mode data $(\sim 11 \mathrm{~km}$ above sea level) within the longitude range of $90-130^{\circ} \mathrm{E}$ and the lower panel shows a time-altitude cross section from ascending and descending data over Singapore. Note that the data in the upper panels are not only from the Singapore flights but from all flights within the range. For the visualisation, the data are all $5 \mathrm{~d}$ running means. Note also that an additional offset of $1.93 \mathrm{ppm}$ is added to the prior mole fractions so that the resulting global offset equals the posterior one. On the righthand side, correlation coefficients and root mean square difference (RMSD) $(\mathrm{ppm})$ between the simulated and observed mole fractions are noted for each time-latitude and time-altitude cross section.

tutes $\sim 80 \%$ of the annual total fire emissions and amounts to more than $80 \%$ of the total net flux we prescribed as the prior (355-360 Tg C) for September-October. By inversion, all experiments, other than $\mathrm{C}_{-} \mathrm{NO}$, estimated smaller total net fluxes than prior data by $\sim 10 \%$ (304-324 Tg C), and they were mostly contributed by the smaller estimates of fire emissions (256-277 Tg C). Interestingly, even when prior fire emissions were excluded in Equatorial Asia (C_NO), high fire emissions of $122 \mathrm{TgC}$ were retrieved for SeptemberOctober, indicating that the CONTRAIL data measure fireemission signals. However, the estimate is half of the others, indicating some dependency of the inversion on the prior fire emissions.

Our conceivably best estimate of CV_GG, which used both the CONTRAIL and NIES VOS data, amounts to 273 and $362 \mathrm{TgC}$ for fire-induced carbon emissions from
September-October and all months in 2015, respectively. These numbers are in better agreement with the previous top-down estimates of Huijnen et al. (2016) (227 Tg C for September-October and $289 \mathrm{Tg} \mathrm{C}$ for the annual total) and Heymann al. (2017) (204 Tg C for July-November) than that of Yin et al. (2016) (510 Tg C for the annual total). Furthermore, the fire-induced carbon emissions of $273 \mathrm{Tg} \mathrm{C}$ for September-October are also consistent with an aerosol-based study by Kiely et al. (2019), the best estimate of which is $247 \mathrm{TgC}$ as the sum of $\mathrm{CO}_{2}$ and $\mathrm{CO}$ emissions for Equatorial Asia but not including eastern areas (e.g. Papua New Guinea). Field et al. (2016) pointed out that the fire emissions estimated by GFED for Equatorial Asia in 2015 are higher than the annual fossil fuel emissions of Japan. Our estimate is smaller than that of GFED but still comparable to 


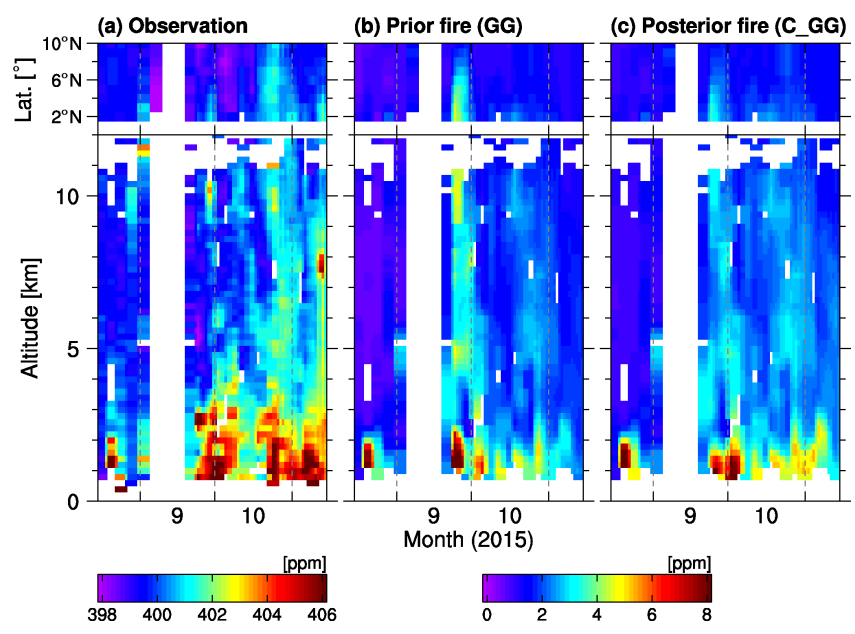

Figure 4. The same as Fig. 3, but for 15 August-15 November. The model simulations here show only fire contributions. (a) $\mathrm{CO}_{2}$ (Sep)

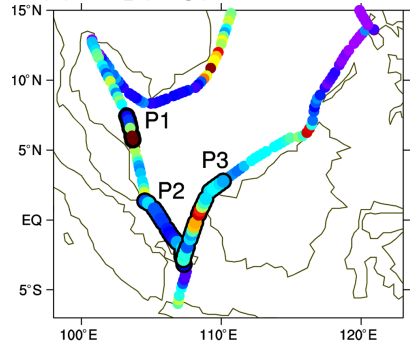

(c) $\mathrm{CO}_{2}$ (Oct)

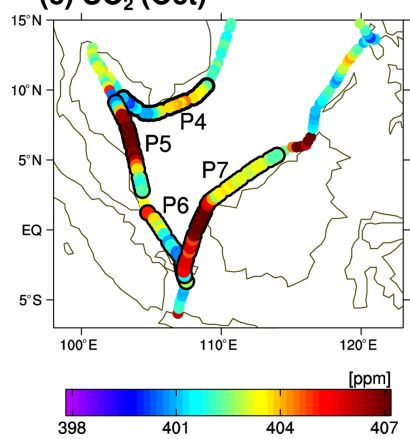

(b) $\mathrm{CO}$ (Sep)

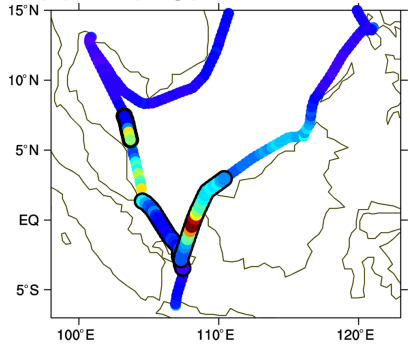

(d) $\mathrm{CO}$ (Oct)

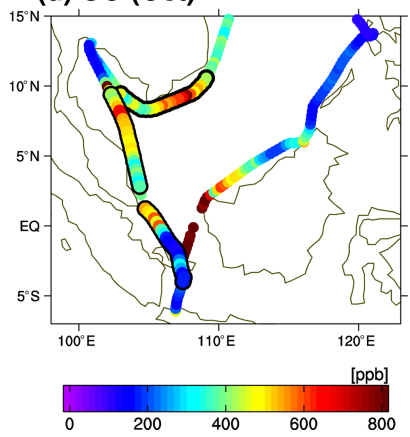

Figure 5. Mole fractions of $\mathrm{CO}_{2}(\mathbf{a}, \mathbf{c})$ and $\mathrm{CO}(\mathbf{b}, \mathbf{d})$ along the cruise tracks of NIES VOS for September $(\mathbf{a}, \mathbf{b})$ and October $(\mathbf{c}, \mathbf{d})$ 2015. Data enclosed by black lines with P\# represent designated fire-induced high mole fraction events (see also Fig. 6).

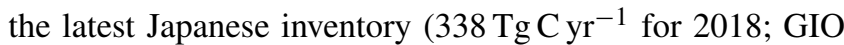
and MOE, 2020).

Figures 8 and 9 show the $\mathrm{CO}_{2}$ flux distributions for September and October, respectively. Here, we present the posterior fluxes of C_GG and C_NO only, but those of the other inversions show similar distribution features to C_GG. In September, C_GG estimated high emissions in Southeast Sumatra and south of Borneo, where the fire emissions dominated in the prior flux (Fig. 8), supporting prior knowledge (a) September

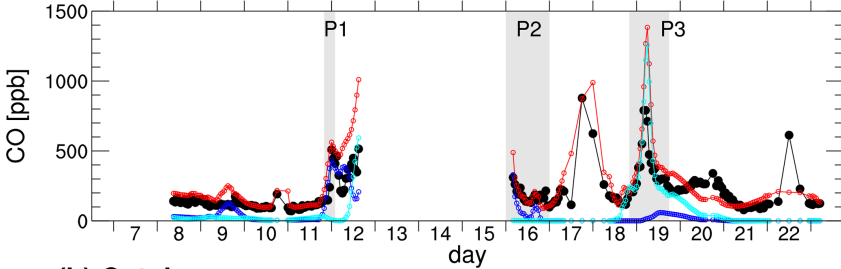

(b) October

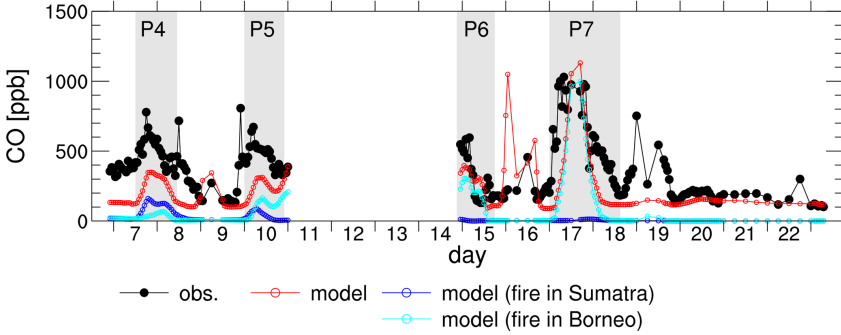

Figure 6. Time series of $\mathrm{CO}$ mole fractions obtained by the in situ NIES VOS measurement (black) for September (a) and October (b) and corresponding simulation results by NICAM-TM with prior $\mathrm{CO}$ emissions data (red). These time series depict the data limited within the range of $95-125^{\circ} \mathrm{E}$ and $10^{\circ} \mathrm{S}-15^{\circ} \mathrm{N}$ consistently with Fig. $5 \mathrm{~b}$ and d. Model simulations only from fire emissions in Sumatra and Borneo are denoted by blue and cyan colours, respectively. Grey shades with P\# indicate the fire-induced elevated mole fraction events.

Table 3. Total net flux and fire emissions of carbon from Equatorial Asia for September-October 2015. Figure 1 defines the geographical region of Equatorial Asia. Note that the total net flux includes terrestrial biosphere fluxes, biomass burnings emissions and fossil fuel emissions. Annual flux values for 2015 are also noted in parentheses. The prior fluxes with the four biomass burning emissions are presented as well as the posterior fluxes of the five inversions.

\begin{tabular}{lrr}
\hline & $\begin{array}{r}\text { Total net flux } \\
(\mathrm{Tg} \mathrm{C})\end{array}$ & $\begin{array}{r}\text { Fire emissions } \\
(\mathrm{Tg} \mathrm{C})\end{array}$ \\
\hline Prior (GG) & $357(677)$ & $299(388)$ \\
Prior (GD) & $360(685)$ & $301(396)$ \\
Prior (GS) & $355(669)$ & $296(379)$ \\
Prior (NO) & $59(289)$ & $0(0)$ \\
C_GG & $324(613)$ & $277(363)$ \\
C_GD & $304(598)$ & $256(343)$ \\
C_GS & $320(604)$ & $265(348)$ \\
C_NO & $211(451)$ & $122(131)$ \\
CV_GG & $322(608)$ & $273(362)$ \\
\hline
\end{tabular}

of biomass burnings. However, the total emissions estimate is smaller than the prior by $31 \mathrm{Tg}$ (Fig. 8c). In October, the differences between prior and posterior fluxes of C_GG were moderate, with a net difference of $2.7 \mathrm{Tg}$ (Fig. 9c). In fact, these flux changes are small compared with the differences between GFED and GFAS (GFED minus GFAS is 92 and $-87 \mathrm{Tg} \mathrm{C}$ for September and October, respectively), indicating that the simulated mole fractions from the prior flux of 
(a) CONTRAIL-SIN (Sep)

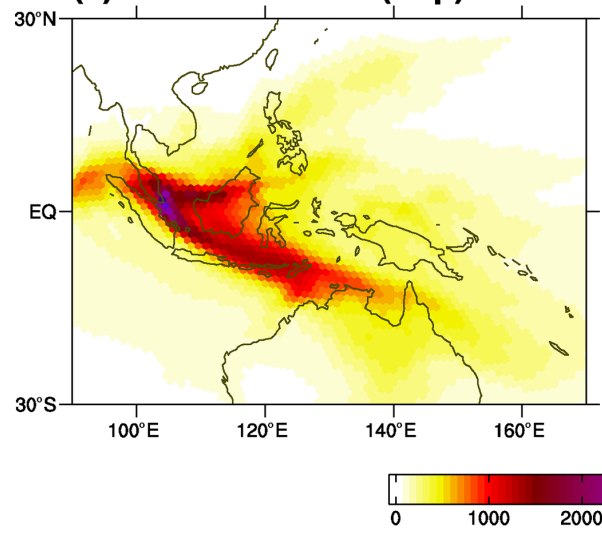

(b) CONTRAIL-SIN (Oct)

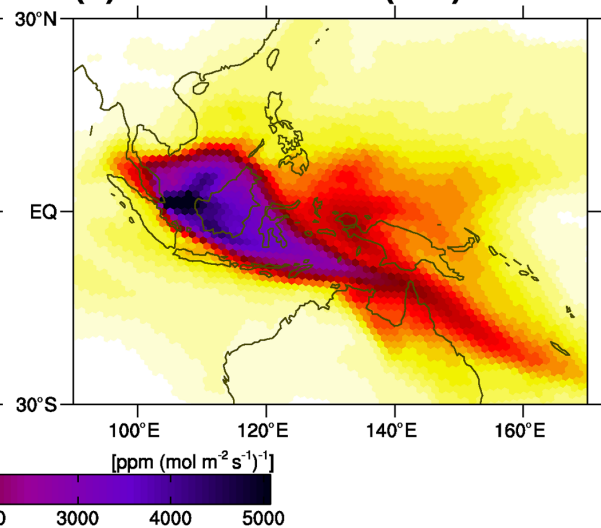

(d) VOS (Oct)

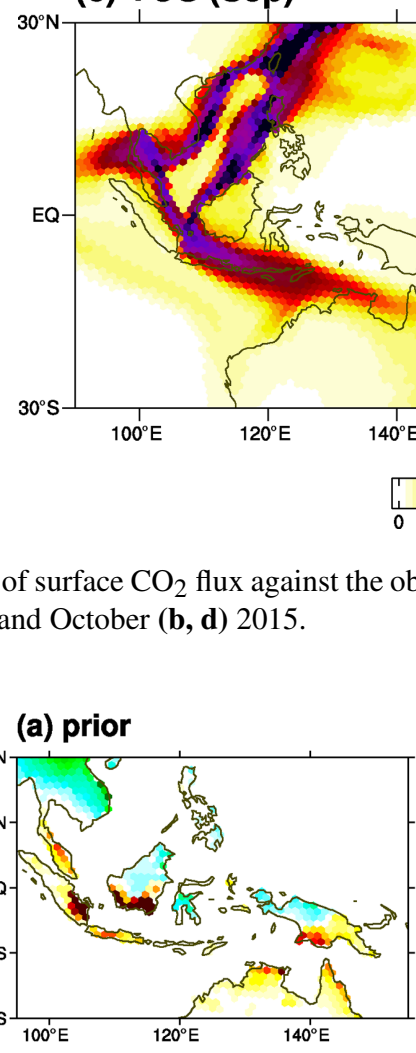

(d) prior (fire)

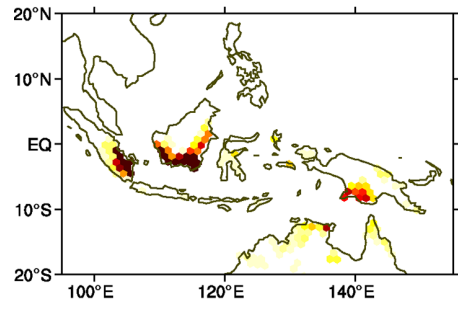

(b) posterior (C_GG)

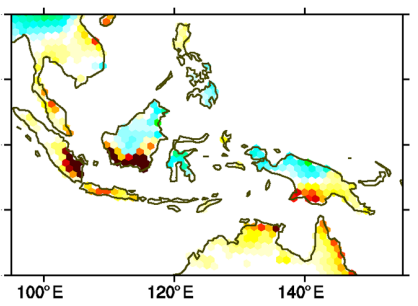

(e) posterior (C_NO)

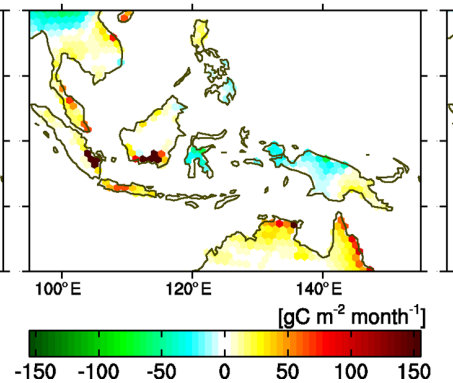

(c) posterior (C GG) - prior

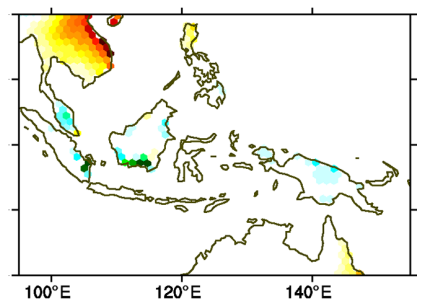

(f) posterior (C_NO) - prior

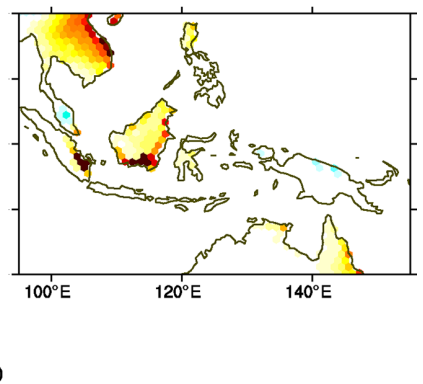

Figure 8. Prior (a) and posterior (b: C_GG, e: C_NO) surface $\mathrm{CO}_{2}$ flux distributions averaged for September 2015. Differences between prior and posterior fluxes (c, f) and prior fire emissions (d) are also shown. Note that the prior estimate of (a) was used both for C_GG and C_NO, while the prior fire estimate of (d) was used only for C_GG. 
(a) prior

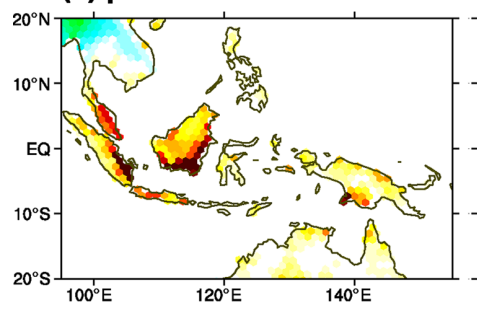

(d) prior (fire)

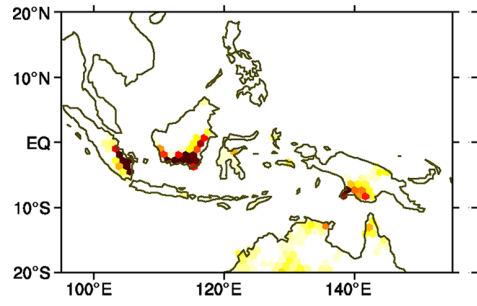

(b) posterior (C_GG)

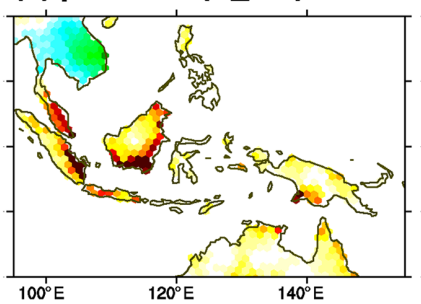

(e) posterior (C_NO)

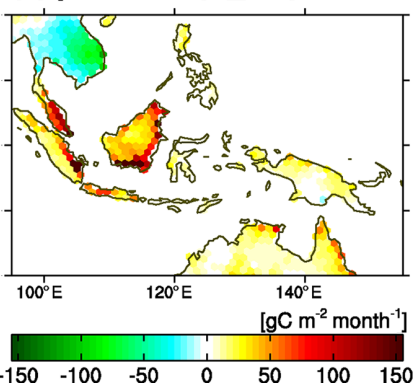

(c) posterior (C_GG) - prior

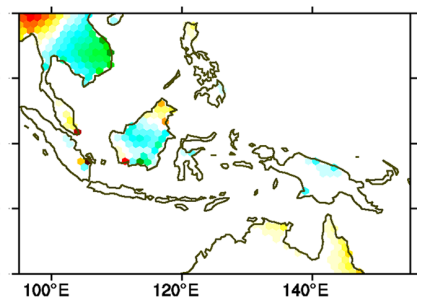

(f) posterior (C_NO) - prior

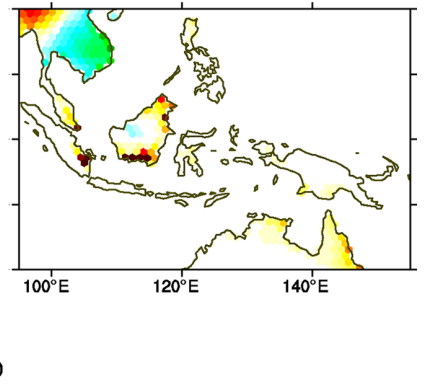

Figure 9. Same as Fig. 8, but for October 2015.

C_GG were overall consistent with the CONTRAIL observations.

As shown in Table 3, even when the fire emissions were excluded from the prior, the inversion estimated notable fire emissions (C_NO) in both September and October (Figs. 8e and 9e). Furthermore, the locations of the estimated fire emissions are well coincident with those of prior fire emissions in Southeast Sumatra and south of Borneo. They were to some extent guided by the higher prior flux errors that were derived from the fire-emission data (the uncertainty was set as $80 \%$ of GG), which was confirmed by another sensitivity test without prior uncertainty of fire emissions (not shown). Nevertheless, this result confirms that the CONTRAIL data have information about biomass burning emissions.

Figure 10 shows temporal variations of the total net carbon flux in Equatorial Asia. Here, the posterior fluxes of C_GG and CV_GG are shown (panel a) and the difference from each prior is presented as $\Delta$ (panel b). Note that the time series of $\Delta$ is smoother because $\Delta$ is the parameter optimised by the inversion with a $3 \mathrm{~d}$ temporal correlation scale. This temporal correlation works as a smoother. The differences between the two posterior fluxes are marginal, indicating a limited effect of adding the NIES VOS data to the CONTRAIL data because the number of CONTRAIL data is overwhelming and the footprint of CONTRAIL covers Equatorial Asia much more extensively in space (Fig. 7). Compared to the prior flux, the posterior fluxes have a smaller peak at the beginning of September, whereas they show larger peaks from the end of September to the beginning of October. In the latter part of October, the prior and posterior fluxes are similar.

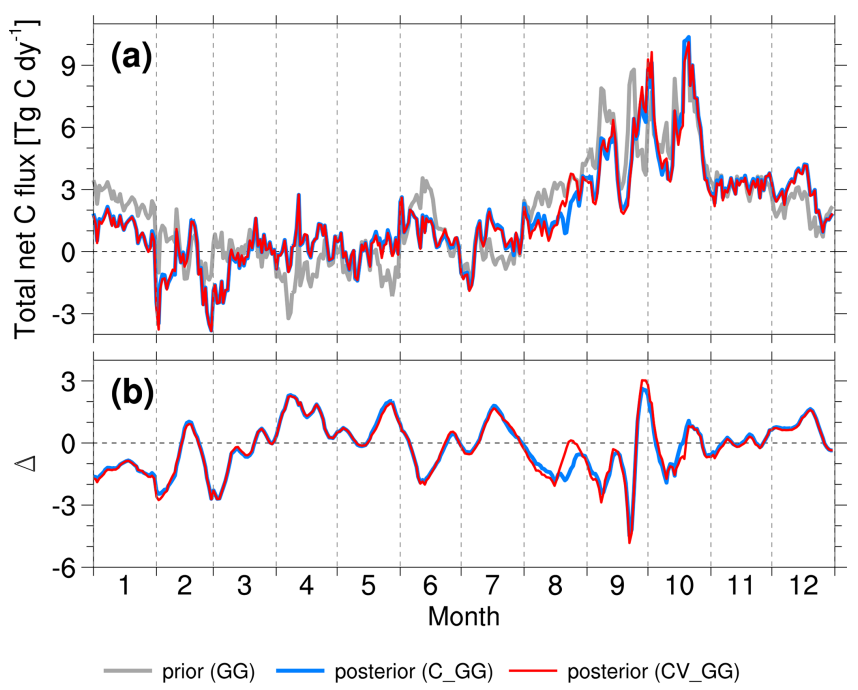

Figure 10. Time series of posterior total net carbon fluxes (a) and their differences from prior $(\Delta)$ (b) for 2015. Posterior fluxes of C_GG (blue) and CV_GG (red) and their prior flux (grey) are presented.

Figure 11 exhibits temporal variations of fire emissions during the fire season. In Equatorial Asia, although the timings of the emission peaks presented by GFED and GFAS are coincident with each other, their magnitudes are significantly different. GFED has larger peaks than GFAS in September, whereas it has smaller ones in October (Fig. 11a). Generally, the posterior fire emissions, except for $\mathrm{C}_{-} \mathrm{NO}$, fall within the range of both prior emission estimates. In September, the posterior estimates are consistent and their magnitudes are closer to GFAS than GFED. In October, however, notable 


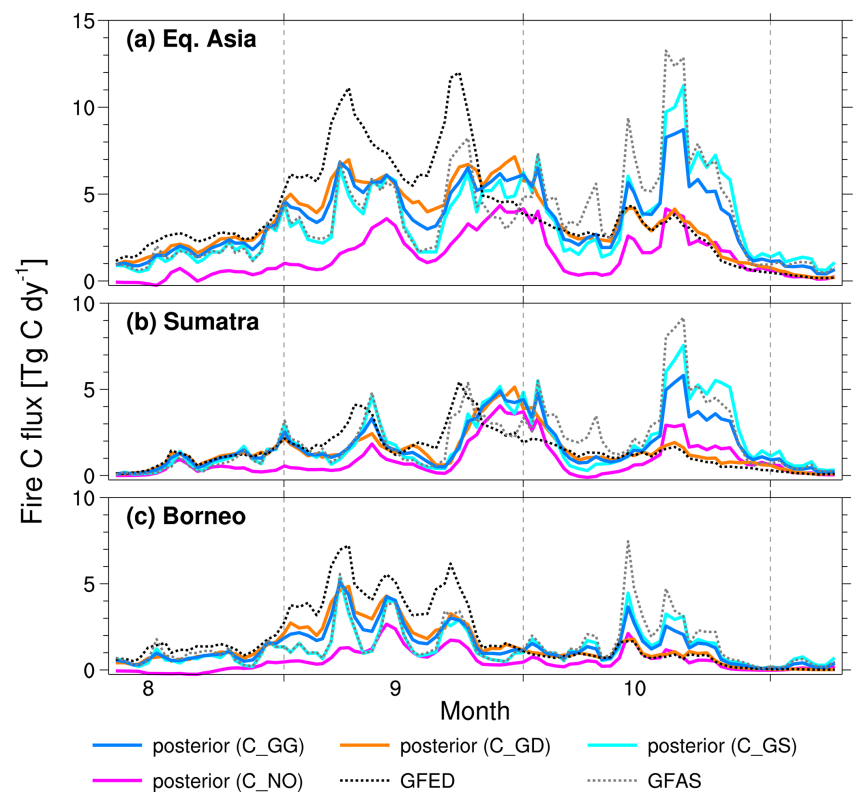

Figure 11. Time series of posterior and prior fire carbon emissions over the fire season (mainly, September-October) of 2015. The posterior fluxes of C_GG (blue solid), C_GD (orange solid), C_GS (cyan solid) and $\mathrm{C}_{-}$NO (magenta solid) are shown. Prior data of GFED (black dotted) and GFAS (grey dotted) are also shown.

discrepancies occur among the posterior emissions, which is contributed by different emission estimates for Sumatra rather than Borneo according to the breakdown of the posterior estimates (Fig. 11b and c). In October, GFAS has higher emissions than GFED on both islands and its degree is more prominent in Sumatra. These different prior fire-emission estimates might have contributed to the large discrepancy among posterior estimates.

As shown in Fig. 7, the CONTRAIL footprint covers Borneo better than Sumatra, and the sensitivity is larger in October than in September. In practice, however, the constraint on fire emissions has a different feature, as seen in the noticeable spread of fire-emission estimates in October (Fig. 11c). Note that the spread of estimates, including C_NO, is small in Sumatra at the end of September (Fig. 11b). In this period, the observational data and model analysis indicated that strong fire signals reached Singapore, although its timing, as suggested by the model, was slightly earlier (Fig. 4b). For this event, the inversion successfully optimised the fire emissions in Sumatra with strong constraints by the observations, even from the no-fire prior (C_NO), resulting in the latershifted peak with the consistent magnitude of $4-5 \mathrm{Tg} \mathrm{C} \mathrm{d}^{-1}$ (Fig. 11b).

\subsubsection{Posterior mole fractions}

In this section, we evaluate the simulated atmospheric $\mathrm{CO}_{2}$ and $\mathrm{CO}$ mole fractions from the posterior fluxes. First, as shown in Fig. 3, the posterior mole fractions of $\mathrm{CO}_{2}$ sim- ulated for CONTRAIL have shown much better agreement with the observations than the prior ones, demonstrating that the inverse analyses were reasonably well performed. Compared to the simulation results of the prior fluxes, the posterior mole fractions have greater correlation coefficients and smaller root mean square differences from the observations (see the numbers at the righthand side of Fig. 3). In the following, we will compare the model with the $\mathrm{CO}_{2}$ and $\mathrm{CO}$ observations of NIES VOS, which were left independent of the inversions, except for CV_GG. As demonstrated by Fig. 2, the posterior $\mathrm{CO}$ flux includes the fire emissions modified according to the modification of $\mathrm{CO}_{2}$ fire emissions. To elucidate carbon fluxes in Equatorial Asia, the NIES VOS data used here are limited in the neighbouring region $\left(95-125^{\circ} \mathrm{E}\right.$ and $\left.10^{\circ} \mathrm{S}-15^{\circ} \mathrm{N}\right)$.

In the comparative analysis of $\mathrm{CO}_{2}$ observations, an additional offset of $1.93 \mathrm{ppm}$ is added to the prior $\mathrm{CO}_{2}$ mole fractions so that the resulting global offset becomes equivalent to the posterior ones, i.e. $\Delta c$ of Eq. (4) is $1.93 \mathrm{ppm}$ (note that there is almost no difference in the global offset among the five inversions). Because the initial global offset was arbitrarily given, the comparison analysis of $\mathrm{CO}_{2}$ should exclude the effect of the improvement in the global offset to better understand the inversion effects.

Figure 12 demonstrates how the posterior mole fractions of $\mathrm{CO}_{2}$ and $\mathrm{CO}$ were improved from the prior ones. Comparing the posterior results with the prior ones, we found better consistency with the NIES VOS observation, which is true for both $\mathrm{CO}_{2}$ and $\mathrm{CO}$. This is especially true for September; all inversions, except CV_GG, reduced the root mean square difference (RMSD) of $\mathrm{CO}_{2}$ from 2.14-2.62 to 2.05$2.09 \mathrm{ppm}$, whereas those of $\mathrm{CO}$ were reduced from 92-211 to $80-111 \mathrm{ppb}$. These results indicate the validity of the inversions that used the CONTRAIL $\mathrm{CO}_{2}$ observations. Meanwhile, the RMSDs of both $\mathrm{CO}_{2}$ and $\mathrm{CO}$ were not necessarily reduced for October. This is attributable to insufficient representativeness of surface fluxes or atmospheric transport, which can be inferred from the larger RMSDs and the smaller correlations in October than those of September. Nevertheless, the experiment without the prior fire emissions (C_NO) exhibited smaller RMSDs with the posterior $\mathrm{CO}_{2}$ and $\mathrm{CO}$ fluxes for both September and October. Furthermore, the improvement in the correlation coefficients is remarkable (in September from 0.43 to 0.56 for $\mathrm{CO}_{2}$ and from 0.34 to 0.81 for $\mathrm{CO}$, whereas in October from 0.29 to 0.49 for $\mathrm{CO}_{2}$ and from -0.18 to 0.49 for $\mathrm{CO}$ ). The other inversions, except for CV_GG, did not improve the correlation coefficients significantly. In both months, CV_GG showed the best scores for $\mathrm{CO}_{2}$, which is reasonable because it used the $\mathrm{CO}_{2}$ observations of NIES VOS. Note, however, that CV_GG used only the $\mathrm{CO}_{2}$ observations but not those of $\mathrm{CO}$. Therefore, the RMSD reduction of CO for September by CV_GG (from 136 to $103 \mathrm{ppb}$ ) demonstrates some improvement in fire emissions. Therefore, it is better to use both the CONTRAIL and NIES VOS observations for flux estimations; however, the 

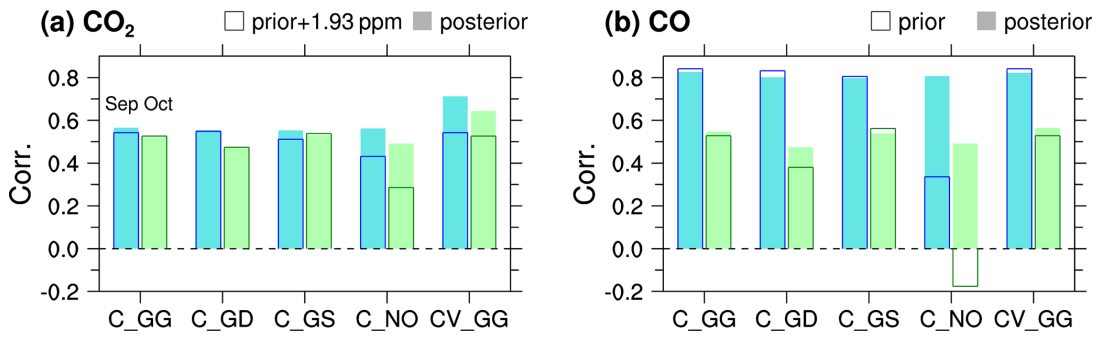

(c) $\mathrm{CO}_{2}$

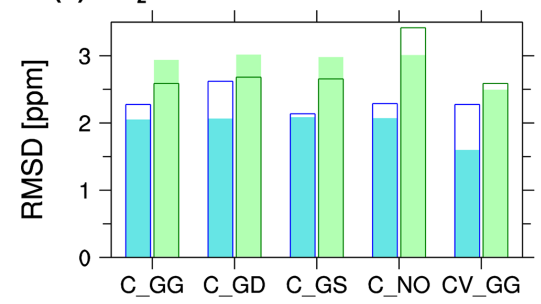

(d) $\mathrm{CO}$

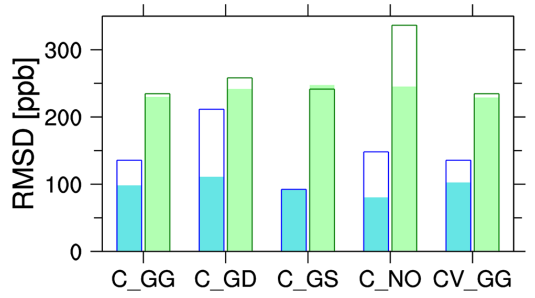

Figure 12. Correlation coefficient (a, b) and root mean square difference (RMSD) (c, d) between the observed and simulated NIES VOS $\mathrm{CO}_{2}(\mathbf{a}, \mathbf{c})$ and $\mathrm{CO}(\mathbf{b}, \mathbf{d})$ mole fractions. The NIES VOS data used here are limited within the range of $95-125^{\circ} \mathrm{E}$ and $10^{\circ} \mathrm{S}-15^{\circ} \mathrm{N}$ for September (light blue) and October (light green) 2015. The model simulations are derived from each posterior flux (C_GG, C_GD, C_GS, C_NO and CV_GG) (filled bar) and its corresponding prior flux (open bar). To consider the initial global offset error, we added 1.93 ppm to every prior value so that the prior initial global offset becomes equivalent to the posterior one.

impact of NIES VOS is limited for the total carbon fluxes in Equatorial Asia (Table 3 and Fig. 10).

For each elevated mole fraction event defined by Figs. 5 and 6, we calculated an enhancement ratio of $\Delta \mathrm{CO} / \Delta \mathrm{CO}_{2}$ from the reduced major axis regression, as done by Nara et al. (2017). For all peaks, except P1 and P2, every correlation between $\mathrm{CO}_{2}$ and $\mathrm{CO}$ variations is statistically significant $(p<0.05)$ for both the observations and simulations. For P1 and P2, some simulated results could not have significant correlations; therefore, we combined the two events so that every correlation was statistically significant (combining $\mathrm{P} 1$ and $\mathrm{P} 2$ would be reasonable because the Sumatra fires contributed to both; see Fig. 6). The enhancement ratios for those events could provide implications for emission ratios between $\mathrm{CO}$ and $\mathrm{CO}_{2}$. Note that the simulated ratios are derived from the posterior fluxes, but the overall feature does not change when the prior fluxes are used because the fireemission ratios between $\mathrm{CO}$ and $\mathrm{CO}_{2}$ were unchanged by the inversion. Figure 13 depicts the observed and simulated enhancement ratios and the observed correlation coefficients for each event. The figure shows that the observed ratio has a significantly large variation from 0.034 to $0.169 \mathrm{ppb} \mathrm{ppb}^{-1}$. Interestingly, the higher ratios were obtained from events that were likely contributed to by the Borneo fires (P3, P6 and P7; see also Fig. 6). The model reproduced a pattern similar to the observed one. However, for the events from September to early October (P1 and P2, P3 and P4), the model coherently overestimated the enhancement ratios. The model and observations, respectively, show $0.067-0.104$ and $0.038 \mathrm{ppb} \mathrm{ppb}^{-1}$ for P1 and P2, 0.139-0.165 and $0.117 \mathrm{ppb} \mathrm{ppb}^{-1}$ for P3, and $0.115-0.133$ and $0.066 \mathrm{ppb} \mathrm{ppb}^{-1}$ for P4. In the latter events,

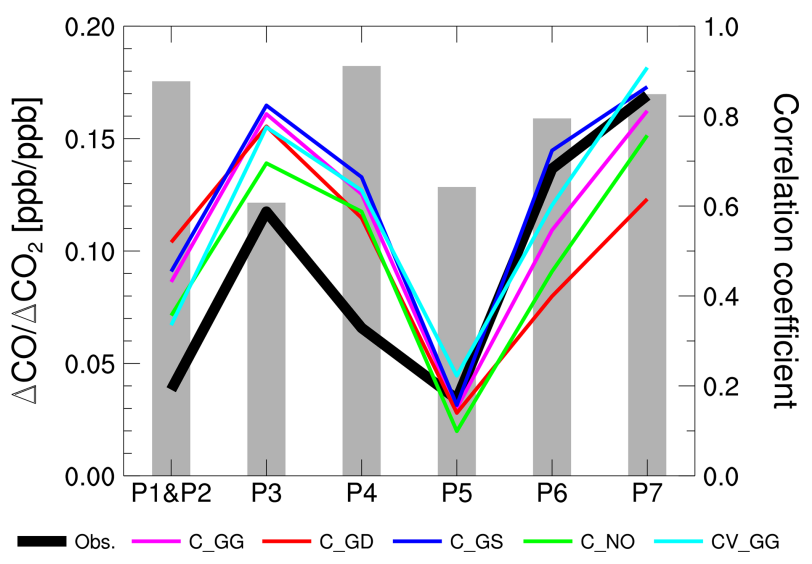

Figure 13. Observed and simulated enhancement ratios of $\Delta \mathrm{CO} / \Delta \mathrm{CO}_{2}$ (solid line) and observed correlation coefficients between $\Delta \mathrm{CO}$ and $\Delta \mathrm{CO}_{2}$ (grey bar) for each elevated mole fraction event defined by Figs. 5 and 6 . The observed enhancement ratios are coloured in black. The simulated values were derived from posterior $\mathrm{CO}$ and $\mathrm{CO}_{2}$ fluxes of C_GG (magenta), C_GD (red), C_GS (blue), C_NO (green) and CV_GG (cyan).

the simulated ratios have substantial spreads among the different inversions, especially for P6 $\left(0.080-0.145 \mathrm{ppb} \mathrm{ppb}^{-1}\right)$ and P7 (0.123-0.182 $\left.\mathrm{ppb} \mathrm{ppb}^{-1}\right)$, and the observed ratios are almost at the highest level of the simulated spreads. This is discussed further in the following section. 


\section{Discussion}

This study used high-precision in situ observations of $\mathrm{CO}_{2}$ to estimate carbon fluxes in contrast to studies that used satellite observations of CO (Huijnen et al., 2016; Yin et al., 2016). Therefore, we obtained the total net carbon flux that included biomass burning emissions, terrestrial biosphere photosynthesis and respiration, and fossil fuel emissions. The estimated total net carbon flux amounts to $322 \mathrm{TgC}$ for September-October (CV_GG), $85 \%$ of which is contributed by fire emissions (Table 3), indicating that flux variations of terrestrial photosynthesis and respiration under severe drought were not as large as those of the biomass burning emissions in 2015. This result indicates that biomass burning emissions are the main driving force of interannual variations of carbon fluxes in Equatorial Asia, which is a unique feature of the carbon fluxes in this region compared with other tropical regions. Carbon fluxes in the tropics are considered to have significant sensitivities to climate variations, especially to El Niño, with major driving forces of terrestrial biosphere flux changes in response to temperature and precipitation changes (Yang and Wang, 2000; Zeng et al., 2005; Wang et al., 2013).

As described in Sect. 2.2, we used a common scaling factor for $\mathrm{CO}_{2}$ and $\mathrm{CO}$ fire fluxes; therefore, the ratio of the emission factors $\left(\mathrm{CO} / \mathrm{CO}_{2}\right)$ was fixed to that of prior fireemission data (GFED and GFAS) and burned carbon mass was modified by the inverse analysis. It is likely that the spatial pattern of fire-emission ratios was reasonably represented because the model reproduced the observed variation in the enhancement ratio that might be caused by the difference in their origins (Figs. 6 and 13). However, as shown in Fig. 13, the model overestimated the enhancement ratios from September to early October, irrespective of its origin (Borneo or Sumatra). Meanwhile, it was not the case for the latter period, although the simulated ranges were large, indicating that the temporal change of the fire-emission ratio, i.e. a decrease of combustion efficiency, might not be well represented in the fire-emission data. Typical fire-emission ratios of $\mathrm{CO} / \mathrm{CO}_{2}$ are $0.2-0.3 \mathrm{~mol} \mathrm{~mol}^{-1}$ for peatlands and $0.1 \mathrm{~mol} \mathrm{~mol}^{-1}$ for tropical forests, respectively (Akagi et al., 2011; Huijnen et al., 2016; Stockwell et al., 2014). Therefore, the observed smaller enhancement ratio infers that the contribution of fires (or smouldering) in dried peatlands was smaller in the early fire period than expected. This might have partially resulted in the smaller-than-prior estimates of the fire-induced carbon emissions (Table 3 ) because peatlands have a high carbon density and are dominant sources of carbon (Page et al., 2002). Nevertheless, the uncertainty is high, as demonstrated by the large model spreads, especially for the latter period, and we need more observations for robust estimations of the fire-emission ratio.

We noted that the inverse analysis of this study has several limitations. First, we employed only $\mathrm{CO}_{2}$ observations in the inverse analysis, which does not allow us to distinguish biomass burnings from other terrestrial fluxes. To separate fire-induced and other terrestrial fluxes, it would be helpful to incorporate $\mathrm{CO}$ observations simultaneously with $\mathrm{CO}_{2}$ observations into the inverse analysis; however, the availability of in situ CO observations (Novelli et al., 2003) is limited, especially for Equatorial Asia. A joint $\mathrm{CO}_{2}-\mathrm{CO}$ inversion is left for a future study.

The second limitation is the dependency of the inverse analysis results on the prior estimate. We found that our inverse calculations had a significant sensitivity to prior fireemission data. The posterior fluxes were similar when GFED or GFAS data were used as the prior. However, when the prior fire emissions were excluded (i.e. C_NO), the posterior flux had much lower values, indicating that we cannot fully constrain the fluxes with CONTRAIL alone and that prior fire-emission data should be as accurate as possible. The relatively small sensitivity to the difference between GFED and GFAS was because the original GFED and GFAS data are comparable. Nevertheless, the well-constrained flux at the end of September in Sumatra (Fig. 11) tells us that we could obtain a sufficient constraint from CONTRAIL when the time and location of the observations coincide with the timing of airflow rich in emission signals. Such an airflow dependency could be reduced by making the observations denser in space and time. To this end, the CONTRAIL project continues its efforts to improve data coverage.

Finally, model transport errors would be the third limitation. Figures 3 and 4 show that even after the inversion, the model could not sufficiently reproduce high mole fractions near the surface, suggesting some limitation of the model. Compared to the wind data obtained from the CONTRAIL aircraft, the speed and direction of winds over Singapore were well simulated in the model (not shown). Therefore, representative errors that include both model transport and fluxes could be one cause. A higher resolution model is desirable and is left for a future study with advanced computational resources.

In this study, we tried a regionally focused inversion using different flux parameter settings for Equatorial Asia and the rest of the world (Table 1), which gave a sufficient degree of freedom to fluxes in Equatorial Asia, while strongly constraining fluxes to the prior ones in the rest of the world. This inversion approach would be acceptable only when prior fluxes can produce comparable spatio-temporal variations of atmospheric $\mathrm{CO}_{2}$ with observations, which was confirmed using the previous inversion flux of Niwa et al. (2012). Furthermore, Niwa et al. (2012) found that CONTRAIL data could independently constrain the fluxes in Equatorial Asia itself, supporting the validity of separating fluxes in Equatorial Asia from those in the other regions. Nevertheless, the inversion flux used as the prior in this study was optimised for different years, which introduced a certain level of uncertainty. In a future analysis, an effort for reducing uncertainties will be made by performing a global inverse analysis by combining ground-based stations and CONTRAIL data. 
In this inversion, we did not calculate the posterior errors, which could give implications of the estimated flux uncertainties. Instead, the spread of the sensitivity tests shows a reasonable range of conceivable flux estimates. In fact, an algorithm for estimating posterior errors was developed by Niwa and Fujii (2020) and it could be applicable to the inverse calculation. However, we left it for a future comprehensive inversion because the algorithm is computationally demanding, especially for the model resolution we used here.

\section{Conclusions}

In this study, an inverse system was developed to estimate high spatio-temporal resolution fluxes in a focused area and incorporate $\mathrm{CO}$ as a proxy for combustion sources. We performed the inverse analysis for carbon fluxes in Equatorial Asia during the historic El Niño of 2015.

In contrast to many studies that used aircraft data for evaluating inversion results as independent data (e.g. Chevallier et al., 2019), we extensively used the CONTRAIL aircraft data in the inverse analysis. Furthermore, with the help of NIES VOS observations, especially its CO data, we demonstrated the validity of our inverse analysis and the fact that the aircraft data could constrain flux estimates efficiently. It is essential for Equatorial Asia because there are insufficient ground-based observations in the region.

We estimated the fire-induced carbon flux to be $273 \mathrm{Tg} \mathrm{C}$ for September-October. This number accounts for $75 \%$ of the annual fire emissions and $45 \%$ of the annual net carbon flux in Equatorial Asia, demonstrating that fire emissions are a major driving force of the carbon flux in the region. Although the inversions have a certain degree of sensitivity to prior fire-emission data, they coherently estimated smaller amounts than the prescribed biomass burning data. One cause could be that peatland fires were not as severe in 2015 as expected, as suggested by the model overestimation of the enhancement ratios $\Delta \mathrm{CO} / \Delta \mathrm{CO}_{2}$ captured by the NIES VOS observation. Nevertheless, this study is compatible with previous studies because a significantly smaller amount of carbon was released in 2015 than in 1997, of which the El Niño intensity was comparable to that of 2015. This could be because the intensity of land-use change has decreased in recent decades (Kondo et al., 2018). Another possible underlying mechanism is the difference in precipitation patterns and amounts between 2015 and 1997 (Fanin and van der Werf, 2017). However, further investigation is needed by combining process-based terrestrial biosphere models, biomass burning emission models and inverse estimates.

Using an atmospheric climate model, Shiogama et al. (2020) projected that Equatorial Asia would experience stronger droughts than that of 2015 in a future warmer climate condition. To reduce fire-induced carbon emissions from such drought events, the chances of ignition must be reduced. The continuous monitoring of carbon emissions with high-precision atmospheric observations is indispensable for mitigation measures against fires. The continuation of the aircraft- and ship-based observations used in this study will ensure the provision of such relevant information and, along with inverse analysis, reliable quantitative estimates of carbon emissions from Equatorial Asia.

Data availability. The $\mathrm{CO}_{2}$ mole fraction data of CONTRAIL (https://doi.org/10.17595/20180208.001, Machida et al., 2018) and NIES VOS used in this study are available from the Global Environmental Database (GED) of NIES (http://db.cger.nies.go.jp/portal/ geds/atmosphericAndOceanicMonitoring?lang=eng, GED, 2019). The CO observational data of NIES VOS are available on request to Hideki Nara (nara.hideki@nies.go.jp).

Author contributions. YN designed and conducted the inversion analyses. TM, YS, HM, YN and TU conducted the CONTRAIL observations and HN, SIN, HT and YT conducted the NIES VOS observations. AI provided the VISIT data. YN prepared the manuscript with contributions from all co-authors.

Competing interests. The authors declare that they have no conflict of interest.

Acknowledgements. Comments from Julia Marshall and an anonymous reviewer helped improve the manuscript. They are greatly appreciated. This study was supported mainly by the Environment Research and Technology Development Fund of the Ministry of the Environment, Japan, and the Environmental Restoration and Conservation Agency of Japan (JPMEERF20142001 and JPMEERF20172001), whose project leader was Nobuko Saigusa of NIES. The work was also supported by the JSPS KAKENHI, Grant Number JP19K03976. The inverse simulations in this study were performed on the NIES supercomputer system (NEC SX-ACE). The observations from the CONTRAIL project are conducted under great support from Japan Airlines, JAMCO and the JAL Foundation. The observational projects of CONTRAIL and NIES VOS are financially supported by the research fund of the Global Environmental Research Coordination System of the Ministry of the Environment, Japan (E1253, E1652, E1851). The NIES VOS programme has been conducted in collaboration with Toyofuji Shipping Co., Ltd and Kagoshima Senpaku Co., Ltd. Yosuke Niwa is grateful to the NICAM developers of the University of Tokyo, JAMSTEC, RIKEN and NIES for maintaining and developing NICAM. Our appreciation is also extended to Tomoko Shirai and Yoko Fukuda of NIES for developing and maintaining GED, through which we make our observational data publicly available.

Financial support. This research has been supported by the Environment Research and Technology Development Fund of the Ministry of the Environment, Japan, the Environmental Restoration and Conservation Agency of Japan (grant nos. JPMEERF20142001 and JPMEERF20172001), the JSPS KAKENHI 
(grant no. JP19K03976) and the Global Environmental Research Coordination System of the Ministry of the Environment, Japan (grant nos. E1253, E1652, and E1851).

Review statement. This paper was edited by Dominick Spracklen and reviewed by Julia Marshall and one anonymous referee.

\section{References}

Akagi, S. K., Yokelson, R. J., Wiedinmyer, C., Alvarado, M. J., Reid, J. S., Karl, T., Crounse, J. D., and Wennberg, P. O.: Emission factors for open and domestic biomass burning for use in atmospheric models, Atmos. Chem. Phys., 11, 4039-4072, https://doi.org/10.5194/acp-11-4039-2011, 2011.

Andres, R. J., Boden, T., and Marland, G.: Monthly FossilFuel $\mathrm{CO}_{2}$ Emissions: Mass of Emissions Gridded by One Degree Latitude by One Degree Longitude, Carbon Dioxide Information Analysis Center, Oak Ridge National Laboratory, U.S. Department of Energy, Oak Ridge, Tenn., USA, https://doi.org/10.3334/CDIAC/ffe.MonthlyMass.2016, 2016.

Baker, D. F., Law, R. M., Gurney, K. R., Rayner, P., Peylin, P., Denning, A. S., Bousquet, P., Bruhwiler, L., Chen, Y., Ciais, P., Fung, I. Y., Heimann, M., John, J., Maki, T., Maksyutov, S., Masarie, K., Prather, M., Pak, B., Taguchi, S., and Zhu, Z.: TransCom 3 inversion intercomparison: Impact of transport model errors on the interannual variability of regional $\mathrm{CO}_{2}$ fluxes, 1988-2003, Global Biogeochem. Cy., 20, GB1002, https://doi.org/10.1029/2004GB002439, 2006.

Chevallier, F., Ciais, P., Conway, T. J., Aalto, T., Anderson, B. E., Bousquet, P., Brunke, E. G., Ciattaglia, L., Esaki, Y., Fröhlich, M., Gomez, A., Gomez-Pelaez, A. J., Haszpra, L., Krummel, P. B., Langenfelds, R. L., Leuenberger, M., Machida, T., Maignan, F., Matsueda, H., Morguiì, J. A., Mukai, H., Nakazawa, T., Peylin, P., Ramonet, M., Rivier, L., Sawa, Y., Schmidt, M., Steele, L. P., Vay, S. A., Vermeulen, A. T., Wofsy, S., and Worthy, D.: $\mathrm{CO}_{2}$ surface fluxes at grid point scale estimated from a global 21 year reanalysis of atmospheric measurements, J. Geophys. Res., 115, D21307, https://doi.org/10.1029/2010JD013887, 2010.

Chevallier, F., Remaud, M., O’Dell, C. W., Baker, D., Peylin, P., and Cozic, A.: Objective evaluation of surface- and satellitedriven carbon dioxide atmospheric inversions, Atmos. Chem. Phys., 19, 14233-14251, https://doi.org/10.5194/acp-19-142332019, 2019.

Christian, T., Kleiss, B., Yokelson, R. J., Holzinger, R., Crutzen, P. J., Hao, W. M., Saharjo, B. H., and Ward, D. E.: Comprehensive laboratory measurements of biomass-burning emissions: 1 . Emissions from Indonesian, African, and other fuels, J. Geophys. Res., 108, 4719, https://doi.org/10.1029/2003JD003704, 2003.

Crisp, D.: Measuring atmospheric carbon dioxide from space with the Orbiting Carbon Observatory-2 (OCO-2), in: Earth Observ. Syst. XX, SPIE, https://doi.org/10.1117/12.2187291, 2015.

Crisp, D., Miller, C. E., and DeCola, P. L.: NASA Orbiting Carbon Observatory: measuring the column averaged carbon dioxide mole fraction from space, J. Appl. Remote Sens., 2, 023508, https://doi.org/10.1117/1.2898457, 2008.
Enting, I. G.: Inverse Problems in Atmospheric Constituent Transport, Cambridge University Press, New York, USA, 2002.

Fanin, T. and van der Werf, G. R.: Precipitation-fire linkages in Indonesia (1997-2015), Biogeosciences, 14, 3995-4008, https://doi.org/10.5194/bg-14-3995-2017, 2017.

Field, R., van der Werf, G., Fanin, T., Fetzer, E., Fuller, R., Jethva, H., Levy, R., Livesey, N., Luo, M., Torres, O., and Worden, H.: Indonesian fire activity and smoke pollution in 2015 show persistent nonlinear sensitivity to El NinPoinduced drought, Proc. Natl. Acad. Sci. USA, 113, 9204-9209, https://doi.org/10.1073/pnas.1524888113, 2016.

Field, R. D., van der Werf, G. R., and Shen, S. S. P.: Human amplification of drought-induced biomass burning in Indonesia since 1960, Nat. Geosci., 2, 185-188, https://doi.org/10.1038/ngeo443, 2009.

Fujii, Y.: Preconditioned Optimizing Utility for Largedimensional analyses (POpULar), J. Oceanogr., 61, 167-181, https://doi.org/10.1007/s10872-005-0029-z, 2005.

Fujii, Y. and Kamachi, M.: A nonlinear preconditioned quasiNewton method without inversion of a first-guess covariance matrix in variational analyses, Tellus A, 55, 450-454, https://doi.org/10.1034/j.1600-0870.2003.00030.x, 2003.

Giglio, L., Randerson, J. T., and van der Werf, G. R.: Analysis of daily, monthly, and annual burned area using the fourthgeneration global fire emissions database (GFED4), J. Geophys. Res., 118, 317-328, https://doi.org/10.1002/jgrg.20042, 2013.

Global Environmental Database (GED): Monitoring of Greenhouse Gases over the Pacific Ocean Using Regular Cargo Ships, available at: http://db.cger.nies.go.jp/portal/geds/ atmosphericAndOceanicMonitoring?lang=eng, last access: 11 October 2019.

Greenhouse Gas Inventory Office of Japan (GIO) and Ministry of the Environment, Japan (MOE) (Eds.): National Greenhouse Gas Inventory Report of JAPAN 2020, Center for Global Environmental Research, National Institute for Environmental Studies, Tsukuba, Japan, 2020.

Guenther, A.: Seasonal and spatial variations in natural volatile organic compound emissions, Ecol. Appl., 7, 34-45, https://doi.org/10.1890/10510761(1997)007[0034:SASVIN]2.0.CO;2, 1997.

Harada, Y., Kamahori, H., Kobayashi, C., Endo, H., Kobayashi, S., Ota, Y., Onoda, H., Onogi, K., Miyaoka, K., and Takahashi, K.: The JRA-55 reanalysis: representation of atmospheric circulation and climate variability, J. Meteor. Soc. Japan, 94, 269-302, https://doi.org/10.2151/jmsj.2016-015, 2016.

Heymann, J., Reuter, M., Buchwitz, M., Schneising, O., Bovensmann, H., Burrows, J. P., Massart, S., Kaiser, J. W., and Crisp, D.: $\mathrm{CO}_{2}$ emission of Indonesian fires in 2015 estimated from satellite-derived atmospheric $\mathrm{CO}_{2}$ concentrations, Geophys. Res. Lett., 44, 1537-1544, https://doi.org/10.1002/2016gl072042, 2017.

Huijnen, V., Wooster, M. J., Kaiser, J. W., Gaveau, D. L. A., Flemming, J., Parrington, M., Inness, A., Murdiyarso, D., Main, B., and van Weele, M.: Fire carbon emissions over maritime southeast Asia in 2015 largest since 1997, Sci. Rep., 6, 26886, https://doi.org/10.1038/srep26886, 2016.

Iida, Y., Kojima, A., Takatani, Y., Nakano, T., Sugimoto, H., Midorikawa, T., and Ishii, M.: Trends in $\mathrm{pCO}_{2}$ and sea-air $\mathrm{CO}_{2}$ flux over the global open oceans for the last two decades, 
J. Oceanogr., 71, 637-661, https://doi.org/10.1007/s10872-0150306-4, 2015

Ito, A.: Disequilibrium of terrestrial ecosystem $\mathrm{CO}_{2}$ budget caused by disturbance-induced emissions and non- $\mathrm{CO}_{2}$ carbon export flows: a global model assessment, Earth Syst. Dynam., 10, 685709, https://doi.org/10.5194/esd-10-685-2019, 2019.

Ito, A. and Inatomi, M.: Use of a process-based model for assessing the methane budgets of global terrestrial ecosystems and evaluation of uncertainty, Biogeosciences, 9, 759-773, https://doi.org/10.5194/bg-9-759-2012, 2012.

Janssens-Maenhout, G., Crippa, M., Guizzardi, D., Muntean, M., Schaaf, E., Dentener, F., Bergamaschi, P., Pagliari, V., Olivier, J. G. J., Peters, J. A. H. W., van Aardenne, J. A., Monni, S., Doering, U., Petrescu, A. M. R., Solazzo, E., and Oreggioni, G. D.: EDGAR v4.3.2 Global Atlas of the three major greenhouse gas emissions for the period 1970-2012, Earth Syst. Sci. Data, 11, 959-1002, https://doi.org/10.5194/essd-11-959-2019, 2019.

Kaiser, J. W., Heil, A., Andreae, M. O., Benedetti, A., Chubarova, N., Jones, L., Morcrette, J.-J., Razinger, M., Schultz, M. G., Suttie, M., and van der Werf, G. R.: Biomass burning emissions estimated with a global fire assimilation system based on observed fire radiative power, Biogeosciences, 9, 527-554, https://doi.org/10.5194/bg-9-527-2012, 2012.

Kiely, L., Spracklen, D. V., Wiedinmyer, C., Conibear, L., Reddington, C. L., Archer-Nicholls, S., Lowe, D., Arnold, S. R., Knote, C., Khan, M. F., Latif, M. T., Kuwata, M., Budisulistiorini, S. H., and Syaufina, L.: New estimate of particulate emissions from Indonesian peat fires in 2015, Atmos. Chem. Phys., 19, 1110511121, https://doi.org/10.5194/acp-19-11105-2019, 2019.

Kobayashi, S., Ota, Y., Harada, Y., Ebita, A., Moriya, M., Onoda, H., Onogi, K., Kamahori, H., Kobayashi, C., Endo, H., Miyaoka, K., and Takahashi, K.: The JRA-55 Reanalysis: General Specifications and Basic Characteristics, J. Meteor. Soc. Japan, 93, 5-48, https://doi.org/10.2151/jmsj.2015-001, 2015.

Kondo, M., Ichii, K., Patra, P. K., Canadell, J. G., Poulter, B., Sitch, S., Calle, L., Liu, Y. Y., van Dijk, A. I. J. M., Saeki, T., Saigusa, N., Friedlingstein, P., Arneth, A., Harper, A., Jain, A. K., Kato, E., Koven, C., Li, F., Pugh, T. A. M., Zaehle, S., Wiltshire, A., Chevallier, F., Maki, T., Nakamura, T., Niwa, Y., and Rödenbeck, C.: Land use change and El Niño-Southern Oscillation drive decadal carbon balance shifts in Southeast Asia, Nature Comm., 9, 1154, https://doi.org/10.1038/s41467-018-03374-x, 2018.

Le Quéré, C., Moriarty, R., Andrew, R. M., Canadell, J. G., Sitch, S., Korsbakken, J. I., Friedlingstein, P., Peters, G. P., Andres, R. J., Boden, T. A., Houghton, R. A., House, J. I., Keeling, R. F., Tans, P., Arneth, A., Bakker, D. C. E., Barbero, L., Bopp, L., Chang, J., Chevallier, F., Chini, L. P., Ciais, P., Fader, M., Feely, R. A., Gkritzalis, T., Harris, I., Hauck, J., Ilyina, T., Jain, A. K., Kato, E., Kitidis, V., Klein Goldewijk, K., Koven, C., Landschützer, P., Lauvset, S. K., Lefèvre, N., Lenton, A., Lima, I. D., Metzl, N., Millero, F., Munro, D. R., Murata, A., Nabel, J. E. M. S., Nakaoka, S., Nojiri, Y., O’Brien, K., Olsen, A., Ono, T., Pérez, F. F., Pfeil, B., Pierrot, D., Poulter, B., Rehder, G., Rödenbeck, C., Saito, S., Schuster, U., Schwinger, J., Séférian, R., Steinhoff, T., Stocker, B. D., Sutton, A. J., Takahashi, T., Tilbrook, B., van der Laan-Luijkx, I. T., van der Werf, G. R., van Heuven, S., Vandemark, D., Viovy, N., Wiltshire, A., Zaehle, S., and Zeng, N.: Global Carbon Budget 2015, Earth Syst. Sci. Data, 7, 349-396, https://doi.org/10.5194/essd-7-349-2015, 2015.
L'Heureux, M. L., Takahashi, K., Watkins, A. B., Barnston, A. G., Becker, E. J., Liberto, T. E. D., Gamble, F., Gottschalck, J., Halpert, M. S., Huang, B., Mosquera-Vaìsquez, K., and Wittenberg, A. T.: Observing and Predicting the 2015/16 El Niño, Bull. Amer. Meteor. Soc., 98, 1363-1382, https://doi.org/10.1175/bams-d-16-0009.1, 2017.

Machida, T., Matsueda, H., Sawa, Y., Nakagawa, Y., Hirotani, K., Kondo, N., Goto, K., Nakazawa, T., Ishikawa, K., and Ogawa, T.: World- wide measurements of atmospheric $\mathrm{CO}_{2}$ and other trace gas species using commercial airlines, J. Atmos. Oceanic Technol., 25, 1744-1754, https://doi.org/10.1175/2008JTECHA1082.1, 2008.

Machida, T., Ishijima, K., Niwa, Y., Tsuboi, K., Sawa, Y., and Matsueda, $\mathrm{H}$.: Atmospheric $\mathrm{CO}_{2}$ mole fraction data of CONTRAIL-CME, Ver.2019.1.0, Center for Global Environmental Research, NIES [data set], reference date: 5 March 2019 , https://doi.org/10.17595/20180208.001, 2018.

Matsueda, H. and Inoue, H. Y.: Aircraft measurements of trace gases between Japan and Singapore in October of 1993, 1996, and 1997, Geophys. Res. Lett., 26, 2413-2416, https://doi.org/10.1029/1999GL900089, 1999.

Matsueda, H., Inoue, H. Y., and Ishii, M.: Aircraft observation of carbon dioxide at $8-13 \mathrm{~km}$ altitude over the western Pacific from 1993 to 1999 , Tellus B, 54, 1-21, https://doi.org/10.1034/j.16000889.2002.00304.x, 2002.

Matsueda, H., Buchholz, R. R., Ishijima, K., Worden, H. M., Hammerling, D., and Machida, T.: Interannual Variation of Upper Tropospheric $\mathrm{CO}$ over the Western Pacific Linked with Indonesian Fires, SOLA, 15, 205-210, https://doi.org/10.2151/sola.2019-037, 2019.

Mu, M., Randerson, J. T., van der Werf, G. R., Giglio, L., Kasibhatla, P., Morton, D., Collatz, G. J., DeFries, R. S., Hyer, E. J., Prins, E. M., Griffith, D. W. T., Wunch, D., Toon, G. C., Sherlock, V., and Wennberg, P. O.: Daily and 3-hourly variability in global fire emissions and consequences for atmospheric model predictions of carbon monoxide, J. Geophys. Res., 116, D24303, https://doi.org/10.1029/2011JD016245, 2011.

Nakaoka, S., Telszewski, M., Nojiri, Y., Yasunaka, S., Miyazaki, C., Mukai, H., and Usui, N.: Estimating temporal and spatial variation of ocean surface $p \mathrm{CO}_{2}$ in the North Pacific using a selforganizing map neural network technique, Biogeosciences, 10, 6093-6106, https://doi.org/10.5194/bg-10-6093-2013, 2013.

Nara, H., Tanimoto, H., Nojiri, Y., Mukai, H., Machida, T., and Tohjima, Y.: Onboard measurement system of atmospheric carbon monoxide in the Pacific by voluntary observing ships, Atmos. Meas. Tech., 4, 2495-2507, https://doi.org/10.5194/amt-4-24952011, 2011.

Nara, H., Tanimoto, H., Tohjima, Y., Mukai, H., Nojiri, Y., and Machida, T.: Emissions of methane from offshore oil and gas platforms in Southeast Asia, Sci. Rep., 4, 6503, https://doi.org/10.1038/srep06503, 2014.

Nara, H., Tanimoto, H., Tohjima, Y., Mukai, H., Nojiri, Y., and Machida, T.: Emission factors of $\mathrm{CO}_{2}, \mathrm{CO}$ and $\mathrm{CH}_{4}$ from Sumatran peatland fires in 2013 based on shipboard measurements, Tellus B, 69, 1399047, https://doi.org/10.1080/16000889.2017.1399047, 2017.

Niwa, Y. and Fujii, Y.: A conjugate BFGS method for accurate estimation of a posterior error covariance matrix in a lin- 
ear inverse problem, Q. J. Roy. Meteor. Soc., 146, 3118-3143, https://doi.org/10.1002/qj.3838, 2020.

Niwa, Y., Tomita, H., Satoh, M., and Imasu, R.: A threedimensional icosahedral grid advection scheme preserving monotonicity and consistency with continuity for atmospheric tracer transport, J. Meteor. Soc. Japan, 89, 255-268, https://doi.org/10.2151/jmsj.2011-306, 2011.

Niwa, Y., Machida, T., Sawa, Y., Matsueda, H., Schuck, T. J., Brenninkmeijer, C. A. M., Imasu, R., and Satoh, M.: Imposing strong constraints on tropical terrestrial $\mathrm{CO}_{2}$ fluxes using passenger aircraft based measurements, J. Geophys. Res., 117, D11303, https://doi.org/10.1029/2012JD017474, 2012.

Niwa, Y., Fujii, Y., Sawa, Y., Iida, Y., Ito, A., Satoh, M., Imasu, R., Tsuboi, K., Matsueda, H., and Saigusa, N.: A 4D-Var inversion system based on the icosahedral grid model (NICAM-TM 4DVar v1.0) - Part 2: Optimization scheme and identical twin experiment of atmospheric CO2 inversion, Geosci. Model Dev., 10, 2201-2219, https://doi.org/10.5194/gmd-10-2201-2017, 2017a.

Niwa, Y., Tomita, H., Satoh, M., Imasu, R., Sawa, Y., Tsuboi, K., Matsueda, H., Machida, T., Sasakawa, M., Belan, B., and Saigusa, N.: A 4D-Var inversion system based on the icosahedral grid model (NICAM-TM 4D-Var v1.0) - Part 1: Offline forward and adjoint transport models, Geosci. Model Dev., 10, 11571174, https://doi.org/10.5194/gmd-10-1157-2017, 2017b.

Novelli, P. C., Masarie, K. A., Lang, P. M., Hall, B. D., Myers, R. C., and Elkins, J. W.: Reanalysis of tropospheric CO trends: Effects of the 1997-1998 wildfires, J. Geophys. Res., 108, 4464, https://doi.org/10.1029/2002JD003031, 2003.

Olsen, S. C. and Randerson, J. T.: Differences between surface and column atmospheric $\mathrm{CO}_{2}$ and implications for carbon cycle research, J. Geophys. Res., 109, D02301, https://doi.org/10.1029/2003JD003968, 2004.

Page, S. E., Siegert, F., Rieley, J. O., Boehm, H.-D. V., Jaya, A., and Limin, S.: The amount of carbon released from peat and forest fires in Indonesia during 1997, Nature, 420, 61-65, https://doi.org/10.1038/nature01131, 2002.

Page, S. E., Rieley, J. O., and Banks, C. J.: Global and regional importance of the tropical peatland carbon pool, Glob. Change Biol., 17, 798-818, https://doi.org/10.1111/j.13652486.2010.02279.x, 2011.

Patra, P. K., Ishizawa, M., Maksyutov, S., Nakazawa, T., and Inoue, G.: Role of biomass burning and climate anomalies for land-atmosphere carbon fluxes based on inverse modeling of atmospheric $\mathrm{CO}_{2}$, Global Biogeochem. Cy., 19, GB3005, https://doi.org/10.1029/2004GB002258, 2005.

Patra, P. K., Houweling, S., Krol, M., Bousquet, P., Belikov, D., Bergmann, D., Bian, H., Cameron-Smith, P., Chipperfield, M. P., Corbin, K., Fortems-Cheiney, A., Fraser, A., Gloor, E., Hess, P., Ito, A., Kawa, S. R., Law, R. M., Loh, Z., Maksyutov, S., Meng, L., Palmer, P. I., Prinn, R. G., Rigby, M., Saito, R., and Wilson, C.: TransCom model simulations of $\mathrm{CH}_{4}$ and related species: linking transport, surface flux and chemical loss with $\mathrm{CH}_{4}$ variability in the troposphere and lower stratosphere, Atmos. Chem. Phys., 11, 12813-12837, https://doi.org/10.5194/acp-11-128132011, 2011.

Randerson, J. T., Thompson, M. V., Conway, T. J., Fung, I. Y., and Field, C. B.: The contribution of terrestrial sources and sinks to trends in the seasonal cycle of atmo- spheric carbon dioxide, Global Biogeochem. Cy., 11, 535-560, https://doi.org/10.1029/97GB02268, 1997.

Randerson, J. T., Chen, Y., van der Werf, G. R., Rogers, B. M., and Morton, D. C.: Global burned area and biomass burning emissions from small fires, J. Geophys. Res., 117, G04012, https://doi.org/10.1029/2012JG002128, 2012.

Rayner, P. J., Enting, I. G., and Trudinger, C. M.: Optimizing the $\mathrm{CO}_{2}$ observing network for constraining sources and sinks, Tellus B, 48, 433-444, https://doi.org/10.3402/tellusb.v48i4.15924, 1996.

Rödenbeck, C.: Estimating $\mathrm{CO}_{2}$ sources and sinks from atmospheric mixing ratio measurements using a global inversion of atmospheric transport, Max-Planck-Institut für Biogeochemie: Technical Paper 6, Jena, Germany, 2005.

Santoso, A., Mcphaden, M. J., and Cai, W.: The Defining Characteristics of ENSO Extremes and the Strong 2015/2016 El Niño, Rev. Geophys., 55, 1079-1129, https://doi.org/10.1002/2017rg000560, 2017.

Satoh, M., Matsuno, T., Tomita, H., Miura, H., Nasuno, T., and Iga, S.: Nonhydrostatic icosahedral atmospheric model (NICAM) for global cloud resolving simulations, J. Comput. Phys., 227, 34863514, https://doi.org/10.1016/j.jcp.2007.02.006, 2008.

Satoh, M., Tomita, H., Yashiro, H., Miura, H., Kodama, C., Seiki, T., Noda, A. T., Yamada, Y., Goto, D., Sawada, M., Miyoshi, T., Niwa, Y., Hara, M., Ohno, T., Iga, S., Arakawa, T., Inoue, T., and Kubokawa, H.: The Non-hydrostatic Icosahedral Atmospheric Model: description and development, Progress in Earth and Planetary Science, 1, 1-32, https://doi.org/10.1186/s40645014-0018-1, 2014.

Sawa, Y., Matsueda, H., Tsutsumi, Y., Jensen, J. B., Inoue, H. Y., and Makino, Y.: Tropospheric carbon monoxide and hydrogen measurements over Kalimantan in Indonesia and northern Australia during October 1997, Geophys. Res. Lett., 26, 1389-1392, https://doi.org/10.1029/1999GL900247, 1999.

Sawa, Y., Machida, T., and Matsueda, H.: Seasonal variations of $\mathrm{CO}_{2}$ near the tropopause observed by commercial aircraft, J. Geophys. Res., 113, D23301, https://doi.org/10.1029/2008jd010568, 2008.

Sawa, Y., Machida, T., and Matsueda, H.: Aircraft observation of the seasonal variation in the transport of $\mathrm{CO}_{2}$ in the upper atmosphere, J. Geophys. Res., 117, D05305, https://doi.org/10.1029/2011jd016933, 2012.

Shiogama, H., Hirata, R., Hasegawa, T., Fujimori, S., Ishizaki, N. N., Chatani, S., Watanabe, M., Mitchell, D., and Lo, Y. T. E.: Historical and future anthropogenic warming effects on droughts, fires and fire emissions of $\mathrm{CO}_{2}$ and $\mathrm{PM}_{2.5}$ in equatorial Asia when 2015-like El Niño events occur, Earth Syst. Dynam., 11, 435-445, https://doi.org/10.5194/esd-11-435-2020, 2020.

Spivakovsky, C., Logan, J. A., Montzka, S. A., Balkanski, Y. J., Foreman-Fowler, M., Jones, D. B. A., Horowitz, L. W., Fusco, A. C., Brenninkmeijer, C. A. M., Prather, M. J., Wofsy, S. C., and McElroy, M. B.: Three-dimensional climatological distribution of tropospheric $\mathrm{OH}$ : update and evaluation, J. Geophys. Res., 105, 8931-8980, https://doi.org/10.1029/1999JD901006, 2000.

Stockwell, C. E., Yokelson, R. J., Kreidenweis, S. M., Robinson, A. L., DeMott, P. J., Sullivan, R. C., Reardon, J., Ryan, K. C., Griffith, D. W. T., and Stevens, L.: Trace gas emissions from combustion of peat, crop residue, domestic biofuels, grasses, and other fuels: configuration and Fourier transform 
infrared (FTIR) component of the fourth Fire Lab at Missoula Experiment (FLAME-4), Atmos. Chem. Phys., 14, 9727-9754, https://doi.org/10.5194/acp-14-9727-2014, 2014.

Takatani, Y., Enyo, K., Iida, Y., Kojima, A., Nakano, T., Sasano, D., Kosugi, N., Midorikawa, T., Suzuki, T., and Ishii, M.: Relationships between total alkalinity in surface water and sea surface dynamic height in the Pacific Ocean, J. Geophys. Res., 119, 2806-2814, https://doi.org/10.1002/2013jc009739, 2014.

Tao, Z. and Jain, A. K.: Modeling of global biogenic emissions for key indirect greenhouse gases and their response to atmospheric $\mathrm{CO}_{2}$ increases and changes in land cover and climate, J. Geophys. Res., 110, D21309, https://doi.org/10.1029/2005JD005874, 2005.

Terao, Y., Mukai, H., Nojiri, Y., Machida, T., Tohjima, Y., Saeki, T., and Maksyutov, S.: Interannual variability and trends in atmospheric methane over the western Pacific from 1994 to 2010, J. Geophys. Res., 116, D14303, https://doi.org/10.1029/2010jd015467, 2011.

Tohjima, Y., Mukai, H., Machida, T., Nojiri, Y., and Gloor, M.: First measurements of the latitudinal atmospheric $\mathrm{O}_{2}$ and $\mathrm{CO}_{2}$ distributions across the western Pacific, Geophys. Res. Lett., 32, L17805, https://doi.org/10.1029/2005GL023311, 2005.

Tomita, H. and Satoh, M.: A new dynamical framework of nonhydrostatic global model using the icosahedral grid, Fluid Dyn. Res., 34, 357-400, https://doi.org/10.1016/j.fluiddyn.2004.03.003, 2004.

Umezawa, T., Matsueda, H., Sawa, Y., Niwa, Y., Machida, T., and Zhou, L.: Seasonal evaluation of tropospheric $\mathrm{CO}_{2}$ over the Asia-Pacific region observed by the CONTRAIL commercial airliner measurements, Atmos. Chem. Phys., 18, 14851-14866, https://doi.org/10.5194/acp-18-14851-2018, 2018.

Umezawa, T., Matsueda, H., Oda, T., Higuchi, K., Sawa, Y., Machida, T., Niwa, Y., and Maksyutov, S.: Statistical characterization of urban $\mathrm{CO}_{2}$ emission signals observed by commercial airliner measurements, Sci. Rep., 10, 7963, https://doi.org/10.1038/s41598-020-64769-9, 2020. van der Werf, G. R., Dempewolf, J., Trigg, S. N., Randerson, J. T., Kasibhatla, P. S., Giglio, L., Murdiyarso, D., Peters, W., Morton, D. C., Collatz, G. J., Dolman, A. J., and DeFries, R. S.: Climate regulation of fire emissions and deforestation in equatorial Asia, Proc. Natl. Acad. Sci. USA, 105, 20350-20355, https://doi.org/10.1073/pnas.0803375105, 2008.

van der Werf, G. R., Randerson, J. T., Giglio, L., van Leeuwen, T. T., Chen, Y., Rogers, B. M., Mu, M., van Marle, M. J. E., Morton, D. C., Collatz, G. J., Yokelson, R. J., and Kasibhatla, P. S.: Global fire emissions estimates during 1997-2016, Earth Syst. Sci. Data, 9, 697-720, https://doi.org/10.5194/essd-9-697-2017, 2017.

Wang, W., Ciais, P., Nemani, R., Canadell, J., Piao, S., Sitch, S., White, M., Hashimoto, H., Milesi, C., and Myneni, R.: Variations in atmospheric $\mathrm{CO}_{2}$ growth rates coupled with tropical temperature, Proc. Natl. Acad. Sci. USA, 110, 13061-13066, https://doi.org/10.1073/pnas.1219683110, 2013.

World Meteorological Organization (WMO): WMO Greenhouse Gas Bulletin, Geneva, Switzerland, 2018.

Yang, X. and Wang, M.: Monsoon ecosystems control on atmospheric $\mathrm{CO}_{2}$ interannual variability: Inferred from a significant positive correlation between year-to-year changes in land precipitation and atmospheric $\mathrm{CO}_{2}$ growth rate, Geophys. Res. Lett. 27, 1671-1674, https://doi.org/10.1029/1999g1006073, 2000.

Yin, Y., Chevallier, F., Ciais, P., Broquet, G., Fortems-Cheiney, A., Pison, I., and Saunois, M.: Decadal trends in global CO emissions as seen by MOPITT, Atmos. Chem. Phys., 15, 1343313451, https://doi.org/10.5194/acp-15-13433-2015, 2015.

Yin, Y., Ciais, P., Chevallier, F., van der Werf, G. R., Fanin, T., Broquet, G., Boesch, H., Cozic, A., Hauglustaine, D., Szopa, S., and Wang, Y.: Variability of fire carbon emissions in equatorial Asia and its nonlinear sensitivity to El Niño, Geophys. Res. Lett., 43, 10472-10479, https://doi.org/10.1002/2016gl070971, 2016.

Zeng, N., Mariotti, A., and Wetzel, P.: Terrestrial mechanisms of interannual $\mathrm{CO}_{2}$ variability, Global Biogeochem. Cy., 19, GB1016, https://doi.org/10.1029/2004gb002273, 2005. 